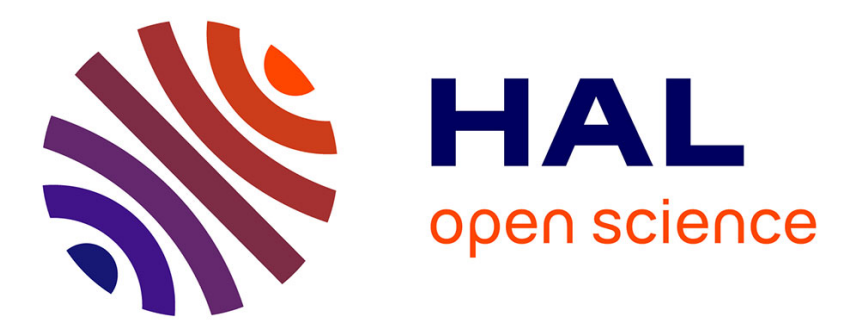

\title{
Suturable elastomeric tubular grafts with patterned porosity for rapid vascularization of $3 \mathrm{D}$ constructs
}

Caroline Bellani, Kan Yue, Florence Flaig, Anne Hebraud, Pengfei Ray,

Nasim Annabi, Heloísa Sobreiro Selistre de Araújo, Marcia Cristina

Branciforti, Ana Maria Minarelli Gaspar, Su Ryon Shin, et al.

\section{To cite this version:}

Caroline Bellani, Kan Yue, Florence Flaig, Anne Hebraud, Pengfei Ray, et al.. Suturable elastomeric tubular grafts with patterned porosity for rapid vascularization of 3D constructs. Biofabrication, 2021, 10.1088/1758-5090/abdf1d . hal-03123479

\section{HAL Id: hal-03123479 \\ https://hal.science/hal-03123479}

Submitted on 27 Jan 2021

HAL is a multi-disciplinary open access archive for the deposit and dissemination of scientific research documents, whether they are published or not. The documents may come from teaching and research institutions in France or abroad, or from public or private research centers.
L'archive ouverte pluridisciplinaire HAL, est destinée au dépôt et à la diffusion de documents scientifiques de niveau recherche, publiés ou non, émanant des établissements d'enseignement et de recherche français ou étrangers, des laboratoires publics ou privés. 


\section{Suturable elastomeric tubular grafts with patterned}

porosity for rapid vascularization of $3 \mathrm{D}$ constructs

Caroline Faria Bellani ${ }^{1,2,3,6,7}$, Kan Yue $e^{6,7,11}$, Florence Flaig ${ }^{2}$, Anne Hébraud ${ }^{2}$, Pengfei Ray ${ }^{6,7}$, Nasim Annabi ${ }^{6,7,8,9}$, Heloísa Sobreiro Selistre de Araújo ${ }^{3}$, Márcia Cristina Branciforti ${ }^{1,4}$, Ana Maria Minarelli Gaspar ${ }^{5}$, Su-Ryon Shin ${ }^{6,7}$, Ali Khademhosseini ${ }^{6,7,8,9,10}$, Guy Schlatter ${ }^{2 *}$

1 Bioengineering Department, Sao Carlos School of Engineering, University of Sao Paulo, Sao Carlos, SP, Brazil.

2 Institut de Chimie et Procédés pour l'Energie, l'Environnement et la Santé (ICPEES), UMR 7515 CNRS-University of Strasbourg, ECPM, Strasbourg, France.

3 Laboratory Biochemistry and Molecular Biology, Physiological Sciences Department, Federal University of Sao Carlos, Sao Carlos, Brazil.

4 Materials Engineering Department, Sao Carlos School of Engineering, University of Sao Paulo, Sao Carlos, SP, Brazil.

5 Department of Morphology, School of Dentistry at Araraquara, São Paulo State University (UNESP), Araraquara, SP, Brazil. 
6 Harvard-Massachusetts Institute of Technology, Division of Health Sciences and Technology, Massachusetts Institute of Technology, Cambridge 02139, MA, USA.

7 Department of Medicine, Brigham and Women's Hospital, Harvard Medical School, Boston 02139, MA, USA.

8 Department of Chemical and Biomolecular Engineering, University of California - Los Angeles, Los Angeles, CA 90095, USA.

9 Center for Minimally Invasive Therapeutics (C-MIT), University of California - Los Angeles, Los Angeles, CA 90095, USA

10 California NanoSystems Institute, University of California - Los Angeles, Los Angeles, CA 90095, USA

11 South China Advanced Institute for Soft Matter Science and Technology, South China University of Technology

Keywords: Electrospinning; laser micromachining; bio-elastomer; vascularization.

\begin{abstract}
Vascularization is considered to be one of the key challenges in engineering functional 3D tissues. Engineering suturable vascular grafts containing pores with diameter of several tens of microns in tissue engineered constructs may provide an instantaneous blood perfusion through
\end{abstract}


the grafts improving cell infiltration and thus, allowing rapid vascularization and vascular branching. The aim of this work was to develop suturable tubular scaffolds to be integrated in biofabricated constructs, enabling the direct connection of the biofabricated construct with the host blood stream, providing an immediate blood flow inside the construct. Here, tubular grafts with customizable shapes (tubes, Y-shape capillaries) and controlled diameter ranging from several hundreds of microns to few $\mathrm{mm}$ are fabricated based on poly(glycerol sebacate) (PGS) / poly(vinyl alcohol) (PVA) electrospun scaffolds. Furthermore, a network of pore channels of diameter in the order of $100 \mu \mathrm{m}$ was machined by laser femtosecond ablation in the tube wall. Both non-machined and laser machined tubular scaffolds elongated more than $100 \%$ of their original size have shown suture retention, being 5.85 and $3.96 \mathrm{~N} / \mathrm{mm}^{2}$ respectively. To demonstrate the potential of application, the laser machined porous grafts were embedded in gelatin methacryloyl (GelMA) hydrogels, resulting in elastomeric porous tubular graft/GelMA 3D constructs. These constructs were then co-seeded with osteoblast-like cells (MG-63) at the external side of the graft and endothelial cells (HUVEC) inside, forming a bone osteon model. The laser machined pore network allowed an immediate endothelial cell flow towards the osteoblasts enabling the osteoblasts and endothelial cells to interact and form 3D structures. This rapid vascularization approach could be applied, not only for bone tissue regeneration, but also for a variety of tissues and organs. 


\section{INTRODUCTION}

Vascularization is considered to be one of the key challenges in tissue engineering [1], and remains the principle obstacle that impedes the translation of most tissue engineered constructs to clinical practice [2]. After construct implantation, the delivery of nutrients to cells on a biomaterial is limited beyond a thickness of approximately $200 \mu \mathrm{m}$ and occurs via interstitial fluid diffusion [3-5]. Most tissue regeneration applications require considerably thicker engineered constructs as, for example, in the case of regeneration after tumor surgery. Spontaneous vascular ingrowth is often limited to several tenths of micrometers per day [6,7], which is too slow to provide adequate nutrients to cells in the interior part of an implant, leading to compromised healing [8].

Biofabrication strategies have been used to pre-vascularize tissue constructs. These strategies employ the creation of hollow channels within the hydrogel itself that can be subsequently perfused with vascular cells [2]. However, the most fundamental question prior to the clinical translation of these constructs is how to connect such a delicate network with the host blood vessels. A microsurgical connection is not achievable due to the insufficient mechanical properties of a biofabricated vessel network made of hydrogels [2]. Therefore, a strategy to overcome these issues may be to include a stronger vascular graft with pore channels inside a biofabricated construct, enabling the direct connection of the construct with the host blood stream, providing an immediate blood flow to the construct.

The success of a vascular graft allowing the rapid vascularization of biofabricated constructs is governed by several characteristics: i) to mimic the extracellular matrix (ECM), providing an adequate environment site for the cells [9]; ii) to have a small diameter in order to be better integrated inside biofabricated tissues, increasing the vascularization area [2]; ii) to be 
biodegradable in order to be remodeled into a new vessel [10]; iii) to be suturable, so it can be anastomosed with the host vasculature, providing an anchor site to the biofabricated graft [2]; iv) and to have an open porosity with a pore diameter in the order of $100 \mu \mathrm{m}$ to allow vascular cell migration and thus, favoring the vascular branching towards biofabricated tissues [2]. An attractive approach to obtain vascular grafts with these features is based on the use of decellularized vessels or grafts $[11,12]$. However, such strategy can lead to undesirable immune responses from the host because of possible antigens of retained cellular remnants [13], as the complete removal of immunogenic foreign biomolecules is challenging [14]. Another disadvantage is the limited supply of human decellularized vessels. Decellularized matrices derived from animal sources could be used but may result in mismatched mechanical properties [15] and involve a risk of transmitting pathogens from the animal source to the human host [16]. Therefore, there is a need for techniques that enable the fabrication of customized vascular grafts with these characteristics.

The electrospinning technique is based on the stretching of a viscoelastic solution into nano/microfibers using a high electrostatic force [17] and offers a valuable tool to produce biomimetic tubular scaffolds with similar architecture to the ECM for tissue engineering [1719]. However, traditional approaches to elaborate electrospun tubular grafts are based on direct electrospinning over a conducting rotating collector [17,20,21], which mostly consists in a cylindrical mandrel. The mandrel must be pre-coated to allow removing of fibers, as they usually stick on the collector surface [22-24]. Furthermore, it is worth noting that the process of electrospinning does not lead to an efficient fiber deposition in the case of cylindrical collectors having a small diameter $[24,25]$. It has also been reported that scaffolds having a tubular shape can be produced using a static working collector with a cylindrical shape perpendicularly fixed to 
an assistant plane collector.[26] Nevertheless, such technique does not allow a precise control and reproducibility of the deposited thickness. Thus, the fabrication of tubular scaffolds by the direct electrospinning on a mandrel, static or not, with diameter smaller than a few millimeters is very difficult especially when the electrospun polymer is very sticky making it almost impossible to remove/detach from the collector. In order to address this issue, single hollow tubes and even multitubular conduits have been produced by simply fabricating a flat scaffold by electrospinning which is further rolled up around one or several needles. Such technique allowed the efficient fabrication of complex nerve grafts having a diameter smaller than $1 \mathrm{~mm} .[27,28]$ We proposed to use such technique which is more appropriate in our case. Another limitation in electrospinning is the formation of fibrous scaffolds with pore diameters smaller than few microns, which does not allow the cell infiltration through the scaffolds. To increase the pore size of electrospun scaffolds, various techniques have been investigated, including the incorporation of porogens [29], the use of patterned collectors [30,31], tuning the fiber diameter [32], ultraviolet radiation treatment [33], and electrospinning with sacrificial fibers [34]. Though interesting, these approaches do not offer a perfect control of the pore patterning or size and thus, they cannot be devoted for the fabrication of scaffolds ensuring an ideal vascular branching. To address this limitation, laser femtosecond micro-ablation or laser machining can be used. Indeed, this technique is considered as a promising tool to rapidly create complex hollow microstructures on electrospun scaffolds [35-37], as the material is removed with minimal thermal damage $[35,38]$.

Poly(glycerol sebacate) (PGS), is a synthetic elastomer which can degrade rapidly in vivo into glycerol and sebacic acid, metabolites that naturally exist in the body, minimizing the duration of host inflammatory response $[39,40]$. However, the direct electrospinning of the crosslinked PGS 
is challenging due to its insolubility resulting from its 3D macromolecular network structure. The pre-polymer of PGS (pPGS) can be easily dissolved to obtain a electrospinning solution [39], however, the pPGS molecular weight is not suitable to produce the molecular entanglements necessary to obtain pPGS-only electrospun fibers [41]. Consequently, the pPGS must be associated with a carrier polymer for the initial processing by electrospinning. Then, a posttreatment is required to crosslink the pPGS in order to obtain elastomeric PGS-based fibrous scaffolds. Jeffries et al.[42] developed a simple method for electrospinning pPGS scaffolds using poly(vinyl alcohol) (PVA) as carrier polymer, which also maintains the fibrous morphology after the crosslinking step. Furthermore, PVA is highly water-soluble and most of the PVA can be removed by washing the scaffold in water, obtaining a PGS blend tubular scaffold with properties as close as possible to the non-modified PGS [42].

The aim of this work was to develop suturable vascular tubular scaffolds with a small inner diameter to be integrated in biofabricated tissue engineered constructs. The tubular scaffolds were developed to connect the constructs to the vascular network providing immediate blood perfusion. We employed PGS combined with PVA to obtain a biodegradable tubular scaffold with suitable elastomeric mechanical properties for application as a vascular graft. We describe a fast and simple technique that enables the fabrication of vascular grafts from electrospinning with a controlled diameter of a few hundreds of microns. Furthermore, a network of pore channels was machined by femtosecond laser micro-ablation, intended to facilitate the endothelialization/vascularization from the vascular graft to the biofabricated construct. The grafts were characterized regarding their morphology, thermal and mechanical properties and their in vitro toxicity. To demonstrate the potential of application of such tubular grafts, the architecture of an osteon (the bone unity constituted of bone layers around a longitudinal 
vascular channel[43,44]) was simulated: $3 \mathrm{D}$ osteon-like constructs were obtained from the coculture of osteoblast-like cells (MG-63) and endothelial cells (HUVECs) in a composite made of gelatin methacryloyl hydrogels (GelMA)/tubular graft system. 


\section{EXPERIMENTAL SECTION}

\section{1. pPGS Synthesis}

We performed the pPGS synthesis assisted by microwave. Briefly, a 1:1 molar ratio of glycerol (4.55 g, 99\%, Sigma-Aldrich) and sebacic acid (10 g, 99\%, Sigma-Aldrich) were mixed together, at room temperature, inside a glass round-bottom flask connected to a glass tube to allow the evaporation of water resulted from the pPGS synthesis. This opening also allows limited evaporation of glycerol. The mixture was placed in a microwave oven (Discover SP®, CEM ${ }^{\mathrm{TM}}$ ) and the synthesis was carried for 180 minutes at $180^{\circ} \mathrm{C}$ at a maximal power $(200 \mathrm{~W})$ under stirring. After this time, a transparent, pale yellow, slightly viscous liquid was obtained, and it was allowed to cool until becoming a white waxy paste. The obtained pPGS was stored at room temperature.

\subsection{Pre-GelMA synthesis}

The GelMA prepolymer (Gelatin Methacryloyl) was prepared as published before [45]. Briefly, the GelMA was fabricated by the direct reaction of gelatin (previously diluted at $10 \%$ in Dulbecco's Phosphate Buffered Saline (DPBS) for one hour at $50^{\circ} \mathrm{C}$ ) with the methacrylic anhydride (MA) in PBS at $50^{\circ} \mathrm{C}$ for two hours. The reaction was interrupted by diluting the obtained product 5 times in PBS. The solution was dialyzed in ultrapure water with a porous membrane of 12-14 $\mathrm{kDa}$ to remove low molecular impurities (i. e. free MA). The material was allowed to be dialyzed for 5 days, at $60^{\circ} \mathrm{C}$. Following, the solution was lyophilized and the GelMA was stored at $-80^{\circ} \mathrm{C}$ until utilization. 


\subsection{Fibrous scaffolds and fibrous tubular scaffolds manufacturing}

\subsubsection{Electrospinning}

Due to its low molecular weight, the pPGS must be electrospun with a carrier polymer that has a higher molecular weight [46]. Since it is necessary to further crosslink the pPGS into PGS after electrospinning, the carrier polymer of choice must have the following criteria: melting temperature above of PGS crosslink temperature; dissolution in a solvent which is common to the pPGS. As suggested in the work of Jeffries et al., we employed PVA as carrier polymer (Gohsenol®, as a generous donation from Nippon Gohsei ${ }^{\mathrm{TM}}, \mathrm{MW} \approx 20,000$ ), because it has a higher melting point than the one required for the crosslink process of PGS, and it is easily removable by water [42]. Additionally, if some PVA remains, it is a non-toxic and noncarcinogenic material [47]. Finally, we employed hexafluorisopropanol (HFIP, Covachem, Ref. 12206-25) as a common solvent for both pPGS and PVA to prepare a solution for electrospinning.

The electrospinning solution was prepared as suggested by Jeffries et al.[42], with some modifications. The pPGS/PVA at a 55:45 (w/w) ratio were diluted at 10\% (w/v) in HFIP, and the solution was kept in magnetic stirring at room temperature overnight, prior to electrospinning. We employed an electrospinning machine assembled in house with a rotating collector (Figure 2A). A voltage of $20 \mathrm{kV}$ has been applied through a positive electrode connected to the tip of the spinneret (electrospinning needle), and $-1 \mathrm{kV}$ to the collector, which was positioned $18 \mathrm{~cm}$ from the spinneret. The solution was put inside a syringe, which has been connected to the spinneret by a polytetrafluoroethylene (PTFE) tube. The flow rate was kept by a syringe pump (Harvard Apparatus ${ }^{\mathrm{TM}}$ ) at $2 \mathrm{ml} /$ hour, controlling the humidity at around $40 \%$ by injecting dry air inside the electrospinning cabin, when necessary. The pPGS/PVA fibers were collected over parchment 
paper (Figure 2A and B). The standard collection time of samples assembled in tubes was 30 minutes.

\subsubsection{Assembly and Scaffolds Crosslinking}

As non-crosslinked pPGS/PVA electrospun membranes are slightly stick, we took advantage of this feature to stack various layers of electrospun scaffolds together, in order to assembly tubular scaffolds, by simply rolling the electrospun pPGS/PVA scaffolds $(10 \mathrm{~cm}$ width $\mathrm{x} 20 \mathrm{~cm}$ length) around PTFE rods (Figure 2B) of $0.75,2$ and $3 \mathrm{~mm}$ of diameter. To investigate mechanical and in vitro properties (cytotoxicity), flat samples have also been crosslinked. The assembled scaffolds were placed in a vacuum oven (Heraeus, Thermo Scientific ${ }^{\mathrm{TM}}$ ) at $150^{\circ} \mathrm{C}$ for 48 hours (Figure 2C), under the minimum pressure achieved assisted by a suction pumping (value between $6-7 \times 10^{-3}$ mbars, as measured by a pressure transducer). We also crosslinked samples at $120^{\circ} \mathrm{C}$ for $24 \mathrm{~h}$, then at $150^{\circ} \mathrm{C}$ for $24 \mathrm{~h}$, for comparison purposes.

\subsubsection{Samples purification}

The samples were washed by immersion in distillated water with gentle agitation at room temperature for 24 hours to remove the PVA (the carrier polymer). Then, to remove the noncrosslinked PGS (i.e. the pPGS), the samples were washed in ethanol 100\%, then in distillated water. For storage and/or analyses, the samples were lyophilized (Figure 2D).

\subsubsection{Laser Micro-ablation}

In order to pattern the tubular scaffolds with porous structures allowing endothelial cells migration, we employed a $1030 \mathrm{~nm}$ femtosecond laser (Amplitude Systèmes) to perform laser 
micro-ablation (or laser machining) and creation of pores. Samples were loaded in a rotor stage and synchronized using computer software (Optec Laser Systems) to fully pattern the tubular scaffold (Figure $2 \mathrm{~F}$ ). The laser energy employed was $1.9 \mathrm{~W}$, with a frequency of $100 \mathrm{kHz}$ and laser beam scanning speed of $250 \mathrm{~mm} / \mathrm{s}$. The pore drilling was performed by pathing a circle of approximately $100 \mu \mathrm{m}$ in diameter by laser beam pulses (size spot around $30 \mu \mathrm{m}$ of diameter) 20 times for complete drilling.

\subsection{Characterization}

\subsubsection{Proton Nuclear Magnetic Resonance $\left({ }^{1}\right.$ H NMR) analysis}

To determine the advancement of the esterification reaction, samples of the pPGS as synthesized were solubilized in deuterated dimethyl sulfoxide (d-DMSO) and analyzed by ${ }^{1} \mathrm{H}$ NMR. The degree of esterification (DE) was calculated, as proposed by Li et al. [48], according to Equation 1 :

$$
D E=\frac{I_{E}}{I_{E}+I_{A}}
$$

Equation 1. Degree of Esterification

where $\mathrm{IE}_{\mathrm{E}}$ is the integration of the $2.28 \mathrm{ppm}$ peak for the esters (- $\left.-\underline{\mathrm{CH}_{2}}-\mathrm{COOR}\right)$, and the $\mathrm{I}_{\mathrm{A}}$ is the integration of the 2.17 peak for the carboxylic acids $\left(-\mathrm{CH}_{2}-\mathrm{COOH}\right)$. The higher the degree of esterification, the higher the polymerization PGS. In this study, we aimed to achieve an ideal degree of esterification equivalent to a pre-polymer of PGS (pPGS), suitable for dilution and for further crosslinking.

\subsubsection{Scanning Electron Microscopy (SEM)}


Morphological aspects of the electrospun scaffolds and of the tubular constructs were analyzed by SEM (Vega 3 TESCANTM). Samples were cut and placed over aluminum stubs with conductive adhesive tape, then they were coated with gold. The average fiber diameter was obtained using ImageJ software (Wayne Hasband, National Institut of Health, USA). An average over 50 measurements for each picture/condition was considered.

\subsubsection{Mass Loss}

We evaluated the removal of PVA and pPGS by mass loss. Samples were weighted after crosslinking, then after the different washing steps, and the masses were compared.

\subsubsection{Mechanical Properties}

Mechanical properties of electrospun PGS/PVA blends were measured by uniaxial tensile testing until their rupture using a hybrid rheometer (Discovery HR-3, TA Instruments), with a pre-load of $0.010 \mathrm{~N}$ and speed of $50 \mu \mathrm{m} / \mathrm{s}$ at room temperature. Crosslinked and purified tubular samples were longitudinally opened, and carefully cut to obtain rectangles of $10 \mathrm{~mm}$ length and $4 \mathrm{~mm}$ width. Sample thickness was measured with a caliper. Four specimens of each sample were obtained and hydrated prior to the measurements. Suture retention strength (SRS) was measured by inserting a 4-0 suture (2mm) from the edge of the long axis of $4 \mathrm{~mm} \times 10 \mathrm{~mm}$ samples and strained to rupture. Suture retention strength was calculated as maximum load/(suture diameter $\mathrm{x}$ sample thickness) in $\mathrm{N} / \mathrm{mm}^{2}$.

To test the interfacial adhesion of the electrospun layers that form the tubular scaffolds, samples for delamination characterization were fabricated by stacking the electrospun scaffolds. Directly electrospun samples were used as control. For the stacked samples, electrospun layers, 
collected for 20 minutes, were stacked with a parchment paper stripe between the layers. For the direct electrospun control, the electrospinning scaffolds were collected over parchment paper for 20 minutes, then a stripe of parchment paper was placed longitudinally to the collector over the sample. The electrospinning was carried for more 20 minutes. These samples were subject to curing with a glass weight over them, and with parchment paper between the weight and the samples. The samples were cured in a vacuum oven at $150^{\circ} \mathrm{C}$ for $48 \mathrm{~h}$ and then purified as described. Prior to mechanical testing, the parchment paper was removed, and the samples obtained had at 3D T-shape (T-peel). Delamination tests were performed on the hydrated T-peel samples.

\subsubsection{Thermogravimetric Analysis (TGA)}

To establish if the samples could be autoclaved, their thermal stability was analyzed by thermogravimetric analyses (TGA) using a Perkin-Elmer thermo-analyzer model Pyris 1. Thermograms were recorded from room temperature to $700^{\circ} \mathrm{C}$ at a heating rate of $10^{\circ} \mathrm{C} / \mathrm{min}$ under nitrogen flow of $20 \mathrm{~mL} / \mathrm{min}$.

\subsection{Cell proliferation/cytotoxicity}

Cell proliferation/cytotoxicity was measured by resazurin (Cat. No R7017, Sigma-Aldrich®), a compound that is reduced and fluoresces in the presence of viable cells and continuous cell proliferation [49]. To prepare the resazurin solution, $1 \mathrm{~g}$ of resazurin powder was diluted in 100 $\mathrm{ml}$ of ultrapure water in magnetic stirring overnight, producing the first resazurin stock solution. We then diluted the stock solution to $10 \%$ in ultrapure water, then filtered it, creating a second stock solution, ready to employ when diluted at $5 \%(\mathrm{v} / \mathrm{v})$ in cell culture media. The cell 
viability/cytotoxicity test was performed according the ISO 10993-5 standard, with biomaterials extract. The extract was prepared by incubating overnight $20 \mathrm{mg}$ of autoclaved PGS/PVA scaffolds per $\mathrm{mL}$ of cell culture media, at $37^{\circ} \mathrm{C}$. Human Umbilical Vein Endothelial Cells (HUVEC) were trypsinized, counted and resuspended at $1 \times 10^{4}$ cells/well. Cells were incubated in DMEM (Vitrocell@, Embriolife ${ }^{\mathrm{TM}}$ ) supplemented with $10 \%$ fetal bovine serum, $1 \%$ penicillin, and $1 \%$ streptomycin $(100 \mathrm{mg} / \mathrm{mL})$ for 3 hours at $37^{\circ} \mathrm{C}, 5 \% \mathrm{CO}_{2}$. Following this, cells were incubated with the scaffolds extract, DMEM only (negative control) or methanol (positive control for cytotoxicity). The extract, cell medium or methanol were changed every 2 days. The cell proliferation assay was performed by incubating with $100 \mu \mathrm{L} 5 \%$ resazurin/DMEM solution per well. We used four wells for each PGS extract, positive and negative control samples, and three independent assays (triplicate). Two empty wells were used as reagent blanks (control of the resazurin). The cells were incubated at $37{ }^{\circ} \mathrm{C}$ in atmosphere supplemented with $5 \%$ of $\mathrm{CO}_{2}$ for $4 \mathrm{~h}$. After incubating, $30 \mu \mathrm{L}$ of medium was transferred into a 96-well TCPS plate, and $30 \mu \mathrm{L}$ of $100 \%$ reduced (fluorescent) resazurin (obtained by autoclaving, as described) was used as a reference for the assay. We measured the fluorescence according to Equation 2. The assay was performed 1, 3, 5 and 7 days after cell seeding.

$$
\text { Relative Fluorescence }(\%)=\frac{(\text { Sample value }- \text { blank })}{(100 \% \text { fluorescent resazurin }- \text { blank })}
$$

Equation 2. Calculation of relative fluorescence of resazurin.

\subsection{GelMA polymerization}

Prior to the polymerization, the photoinitiator solution (PI) was prepared by adding $10 \mathrm{mg}$ of 2-Hydroxy-4'-(2-hydroxyethoxy)-2-methylpropiophenone (Sigma-Aldrich 410896-10G) in $1 \mathrm{ml}$ of ultrapure water, vortexing the solution and keeping it at $60^{\circ} \mathrm{C}$. The pre-GelMA was diluted to 
$10 \%(\mathrm{~m} / \mathrm{v})$ in PBS, and this solution was also kept at $60^{\circ} \mathrm{C}$ for at least 1 hour, in order to completely dissolve the pre-GelMA, creating the stock pre-GelMA. Following the dissolution steps, all solutions were kept at $37^{\circ} \mathrm{C}$. The pre-GelMA solution was made by mixing the PI solution to a final concentration of $0.1 \%(\mathrm{~m} / \mathrm{v})$, the pre-GelMA stock solution to $5 \%(\mathrm{~m} / \mathrm{v})$ and EBM-2 + bullet kit cell culture media (Lonza $\left.{ }^{\circledR}\right)$. This pre-GelMA solution was transferred to the wells of a $96-$-well transparent TCPS plate $(40 \mu \mathrm{l} /$ well). The plate was placed inside a UV curing chamber ( $375 \mathrm{~nm}, 36 \mathrm{w})$ and the polymerization was performed for 15 minutes.

\subsection{HUVEC/MG-63 3D co-culture on GelMA}

3D co-culturing of osteoblasts and endothelial cells has been widely reported [50-54]. Osteoblast-like MG-63 cells are derived from a malignant tumor and retain osteoblastic features [55]. This is a stable immortal lineage, which has often been used with a number of materials for in vitro assays [56]. HUVEC cells are widely used as angiogenesis model for vascularization in vitro [57].

The GelMA was polymerized as previously described and 3D cultures of osteoblasts and endothelial cells were seeded directly on the polymerized GelMA, simulating the seeding which would be performed for the assembling of vascular grafts with GelMA. Osteoblasts were first seeded at $1 \times 10^{4}$ suspended at $40 \mu \mathrm{l}$ of EBM-2 bullet kit media, then they were allowed to adhere on GelMA for 1 hour. The cell media was then removed and the HUVEC cells were seeded at 2 X $10^{4}$ cells/well (double the concentration of MG-63 because HUVEC cells are less proliferative [52]) in $15 \mu \mathrm{l}$ of media for 30 minutes (to allow cell adhesion and, at the same time, to prevent cell dehydration). Finally $120 \mu \mathrm{l}$ of cell culture media was added to each well. These steps were performed in order to keep the majority of HUVECs in the middle of the hydrogel, so we could 
create a gradient of HUVECs towards the osteoblasts. After 48 hours, the constructs were fixed and stained as it will be further described.

\subsection{Fluorescent Staining}

Cells were fixed with $4 \%$ of paraformaldehyde in PBS for 10 minutes and washed twice with PBS. Cells were permeabilized in a solution of $0.1 \%$ of triton $\mathrm{x}-100$ in PBS for 5 minutes. The wells were washed twice with PBS. Cells were incubated with DAPI (provided by SigmaAldrich) and Phalloidin (CytoPainter Phalloidin-iFluor 488, Cat. $\mathrm{N}^{\circ}$ 176753, Abcam ${ }^{\mathrm{TM}}$ ) diluted in PBS with 1\% BSA as per the manufacturer's recommendations. After 10 minutes, the samples were washed twice with PBS. For the last wash, some PBS was left to prevent sample dehydration. The light and fluorescence images from samples were taken from a Zeiss Axio Vert.A1 inverted microscope with AxioCam software. The images were superimposed (DAPI and GFP filters and their superimposition with the light microscopy images, as illustrated in Figure S1). Noise reduction and contrast improvement filters were applied.

\subsection{Endothelial Cells Seeding from the Vascular Graft: an in vitro model of bone vascularization (osteon-like) from the PGS vascular grafts embedded in GelMA}

As one of the hypotheses of this work is that the porous structure, created by laser ablation, on the fibrous PGS/PVA scaffolds allows the endothelialization from the scaffold towards a bonelike tissue engineering construct, we created an in vitro model which simulates the rapid cell perfusion from the vascular scaffolds to a 3D bone construct, in order to observe how endothelial cells migrate towards and/or interact with a 3D bone-like biofabricated construct. 
This construct was designed to be osteon-like $[43,44]$, containing the central blood capillary, represented by the vascular graft and the vascular endothelial cells (HUVECs), and the concentric osseous lamellae, represented by the osteoblast-like cells (MG-63). An overview of the assembly is shown in Figure 1. First, transversal sections of non-patterned (without micropores) and laser patterned scaffolds (with micropores) were embedded inside noncrosslinked GelMA (pre-GelMA) in a well of a 96 well-plate (Figure 1A and B). The GelMA could be crosslinked for 15 minutes, fixing the tubular scaffold (Figure 1C). Suspended MG-63 were seeded at $1 \times 10^{4}$ per well $(40 \mu \mathrm{l})$, over GelMA, outside the graft. The MG-63 were allowed to adhere at GelMA substrates for 30 minutes prior to HUVEC seeding $\left(2 \times 10^{4} /\right.$ well, suspended in $15 \mu \mathrm{l}$ of cell culture media), creating a gradient of HUVECs and MG-63 (Figure 1D). For the machined scaffolds it is worth pointing out that, inevitably, HUVECs escaped from the scaffold and MG-63 entered through the micropores during seeding. After 48 hours, the constructs were fixed and stained with phalloidin and DAPI, as reported, and observed by a fluorescence microscope. 
A Filling wells plate with liquid Pre-GelMA

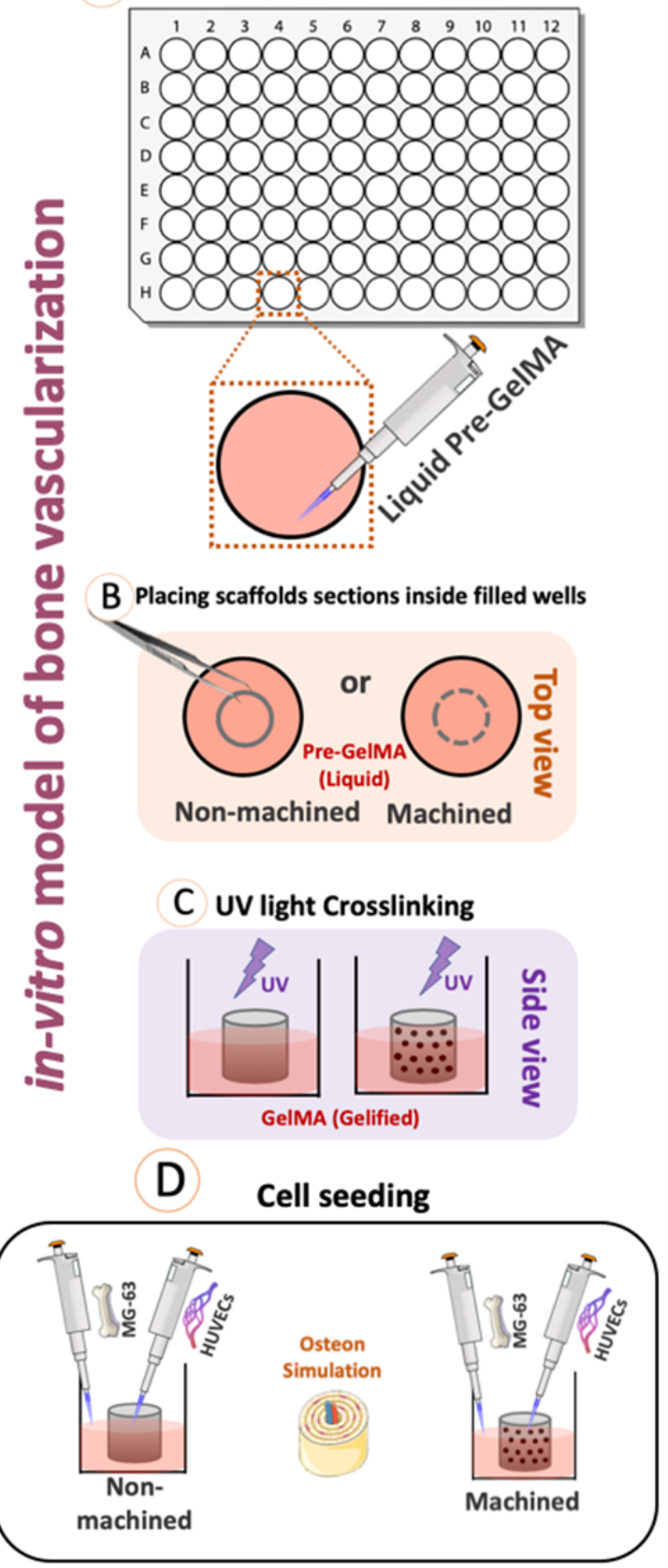

Figure 1. in vitro model of bone vascularization (osteon-like) from the PGS vascular grafts embedded in GelMA: (A) First, empty TCPS wells of a 96-wells plate were filled with liquid GelMA prepolymer. (B) Then, transversal cuts of tubular scaffolds (non-machined and machined), were embedded into liquid GelMA, and placed in the middle of the well. (C) The 
GelMA was crosslinked by UV light with the scaffold inside. (D) Dynamic cell seeding, as simulation of an osteon: the endothelial cells were seeded inside the tubular scaffold, while the osteoblasts were seeded at the external side of the scaffold (considering proper times for cells to adhere, as described).

\subsection{Statistical Analysis}

Statistical comparisons were performed using two-way ANOVA carried out with GraphPad Prism ${ }^{\circledR}$ software and the Bonferroni multiple comparisons test. P-values $<0.05$ were considered statistically significant $(\mathrm{n}=4)$.

\section{RESULTS}

\subsection{Fabrication of vascular graft overview}

In the context of rapid vascularization in tissue engineering, vascular grafts, which are embedded in complex biofabricated 3D constructs, must ensure immediate blood flow from the host to the whole construct. Thus, in this work, we propose the elaboration of fibrous tubular elastomeric vascular grafts with pores of a diameter in the order of $100 \mu \mathrm{m}$. The several steps allowing the fabrication of a tubular graft are depicted in the Figure 2. Briefly, a nanofibrous scaffold was first elaborated by electrospinning a solution of a pre-polymer of PGS (pPGS) and poly (vinyl alcohol) (PVA) as a carrier polymer, using a rotating collector insuring a homogeneous deposition of the fibers (Figure 2A). Following, the tube was assembled by rolling the fibrous scaffold around a PTFE mandrel with different diameters (Figure 2B) and then in a Y-shape (Figure 2E and Movie S1). The presence of pPGS, which is slightly adhesive, allowed a simple assembling of the tube while keeping its shape after its manufacturing. Then, the 
assembled tubes were thermally crosslinked under vacuum in order to cure the pPGS into PGS, which also leads to the welding of the electrospun layers of the scaffold (Figure 2C). The obtained tubes were washed in $\mathrm{dH}_{2} \mathrm{O}$ to remove the carrier polymer (PVA) and in ethanol to remove possible traces of pPGS. The tubes were then freeze-dried (Figure 2D). Elastomeric fibrous tubular scaffolds with various calibers - as small as $0.73 \mathrm{~mm}$ - and clinically relevant lengths could easily be obtained thanks to the described assembly process, which also allows some liberty of forms, e.g. the illustrated Y-shape tubular scaffold (Figure 2E and Movie S1). Finally, laser micromachining post-processing was performed in order to create a network of pore channels of diameter in the order of $100 \mu \mathrm{m}$ to potentially promote vascular branching inside biofabricated constructs ( Figure $2 \mathrm{~F})$. Through this process, fibrous elastomeric tubes with a patterning of pores having a diameter in the range of $100 \mu \mathrm{m}$ were produced. The detailed results of each of these steps will be described. 


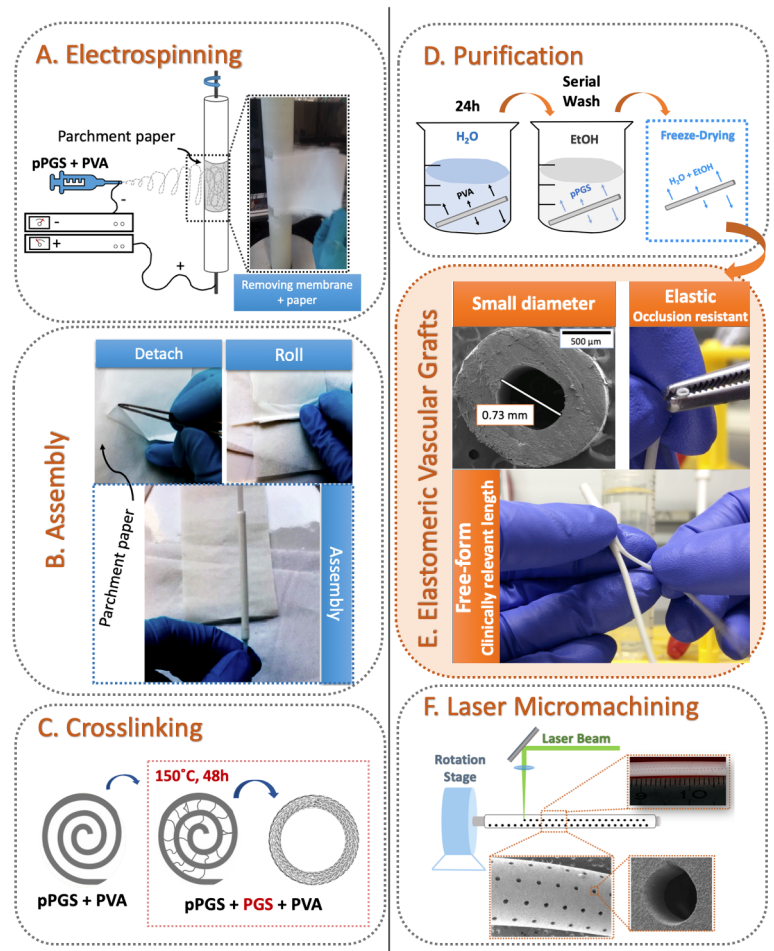

Figure 2. Overview of the fabrication process of bioabsorbable and elastomeric vascular grafts. (A) Electrospinning of pPGS and PVA on a non-sticky parchment paper using a rotating collector to insure the homogeneity of the scaffold. (B) Assembly of the tubular scaffolds by detaching the electrospun scaffolds and rolling them around PTFE mandrels. (C) Crosslinking the pPGS into PGS, which also leads to the fusing of electrospun layers of the scaffold. (D) Purification of the scaffolds by $\mathrm{dH} 2 \mathrm{O}$, to remove the PVA, then by serial washing with ethanol to remove possible traces of pPGS, followed by freeze-drying the obtained scaffolds. (E) The obtained tubular scaffolds can have very small inner diameters, clinically relevant lengths and some liberty of forms (Y-shape). (F) Laser femtosecond micro-ablation post-processing, which does not melt the fibers. Through this process, tubular scaffolds with a patterning of porous at the microscale were produced. 


\subsection{Characterization of elastomeric PGS fibrous scaffolds}

\subsubsection{PGS fibrous scaffolds crosslinking optimization}

A poly (glycerol sebacate) prepolymer (pPGS) with a soft wax aspect, as described by Li et. al.[48] was synthesized, with an estimated degree of esterification of $51 \%$, as measured by ${ }^{1} \mathrm{H}$ NMR (see Figure S2). Following, pPGS was employed to produce pPGS/PVA (55/45 weight ratio) fibrous scaffolds by electrospinning from $10 \%(\mathrm{w} / \mathrm{v})$ solutions in hexafluoroisopropanol (HFIP).

The morphology of the electrospun scaffolds were observed by SEM after their collection on parchment paper (Figure 3A), their crosslinking in different conditions (Figure 3B, C and D), followed by their $\mathrm{dH} 2 \mathrm{O}$ and serial EtOH washings to remove PVA and uncrosslinked pPGS chains. The conditions allowing the crosslinking of PGS/PVA scaffolds were adapted from the work reported by Jeffries et al., who reported various curing temperature and time to crosslink their PGS/PVA membranes under vacuum. They concluded that the best condition, in terms of mechanical properties and integrity of fibers preservation, was $120^{\circ} \mathrm{C}$ for $48 \mathrm{~h}$ [42]. We investigated this crosslinking condition in our lab, as well as curing at $120^{\circ} \mathrm{C}$ for $24 \mathrm{~h}$, followed by $150^{\circ} \mathrm{C}$ for 24 more hours, or curing at $150^{\circ} \mathrm{C}$ for $48 \mathrm{~h}$. In our case, only a curing step of $48 \mathrm{~h}$ at $150^{\circ} \mathrm{C}$ allowed to obtain samples with a uniform morphology and preserved porosity (Figure $\underline{3} \mathrm{D}$ ), while a film or fused fibers were obtained for the two other tested conditions (Figure 3B, C, respectively). Therefore, all the following fibrous scaffolds described in this work were crosslinked under vacuum at $150^{\circ} \mathrm{C}$ for $48 \mathrm{~h}$.

The PVA purification efficiency was estimated by mass loss, from the different crosslinking conditions (Figure 3E). The remaining mass at $150^{\circ} \mathrm{C}, 48 \mathrm{~h}$ condition was higher than for $120^{\circ} \mathrm{C}$ - 
$24 \mathrm{~h}$ and $150^{\circ} \mathrm{C}-24 \mathrm{~h}$, after both water and ethanol washes, indicating that a significant amount of mass remained after the water washing for the $150^{\circ} \mathrm{C} 48 \mathrm{~h}$ condition in comparison with the $120^{\circ} \mathrm{C}-24 \mathrm{~h}, 150^{\circ} \mathrm{C}-24 \mathrm{~h}$ condition. This thermal annealing may contribute for PVA insolubility [58] due to its possible crosslinking with the residual carboxylic groups of the pPGS.[42] For both crosslinking conditions, the most significant mass loss was measured after water washing, which most likely removes the PVA, due to its solubility in water. A significant amount of mass remained after the water washing for the $150^{\circ} \mathrm{C} 48 \mathrm{~h}$ condition in comparison with the $120^{\circ} \mathrm{C}$ $24 \mathrm{~h}, 150^{\circ} \mathrm{C}-24 \mathrm{~h}$ condition. Finally, the mass loss after washing in ethanol is also lower in the case of crosslinking reaction at $150^{\circ} \mathrm{C}$ for $48 \mathrm{~h}$ indicating that less uncrosslinked pPGS has been removed at this step. 


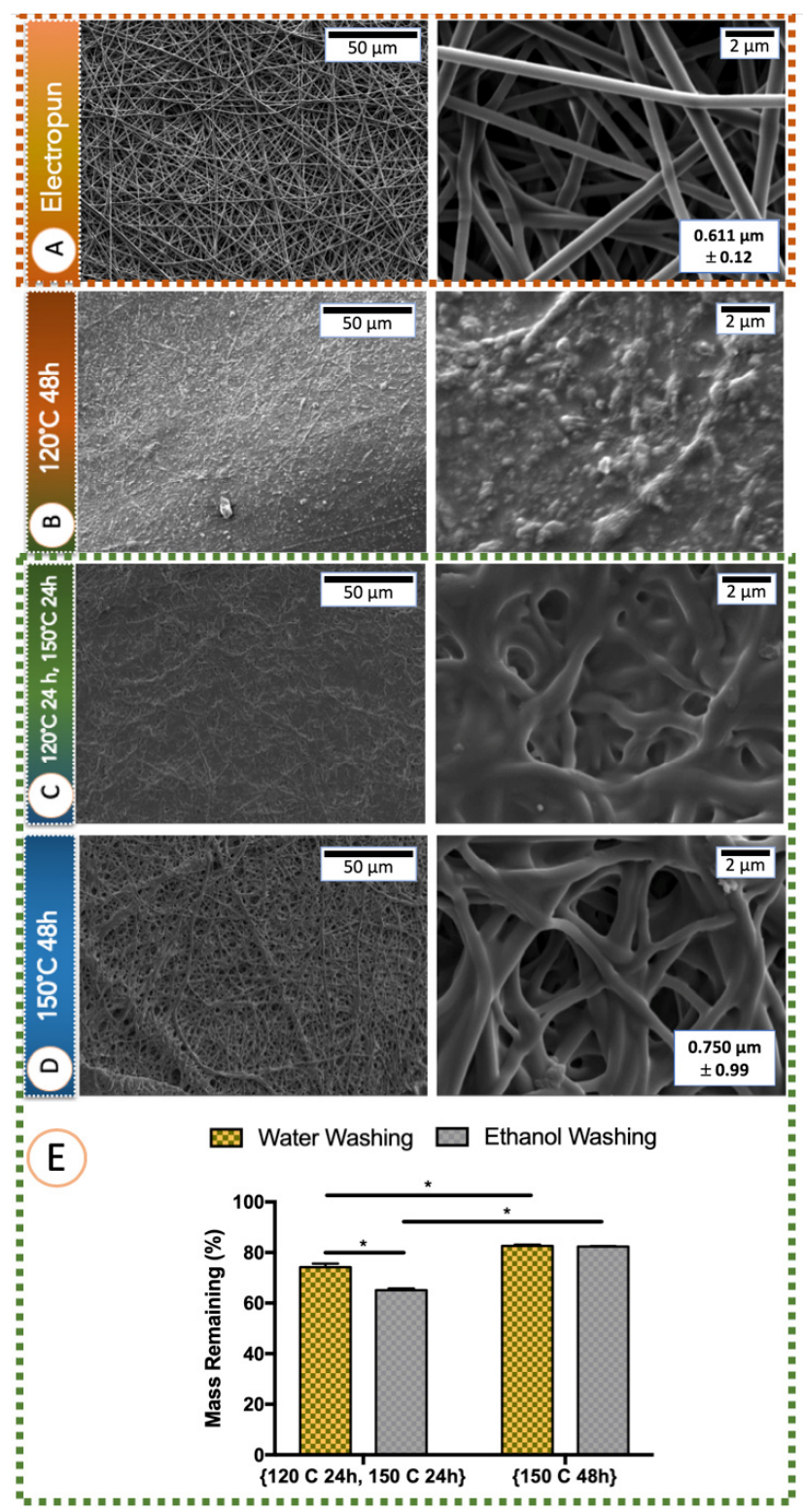

Figure 3. SEM images of (A) electrospun pPGS/PVA scaffolds; and crosslinked and purified at different conditions: (B) $120^{\circ} \mathrm{C} 48 \mathrm{~h}$; (C) $120^{\circ} 24 \mathrm{~h}$, then $150^{\circ} \mathrm{C} 24 \mathrm{~h}$; and (D) $150^{\circ} \mathrm{C} 48 \mathrm{~h}$. The overall morphology of the scaffolds is shown. In the square on the electrospun and crosslinked at $150^{\circ} \mathrm{C} 48 \mathrm{~h}$ images, the average diameter \pm Standard Deviation of the Mean are displayed. (E) scaffolds purification efficiency calculated by the average remaining mass $(\%, \mathrm{n}=3)$ after each 
washing step (water washing and ethanol serial washing) in comparison with the crosslinked samples. Error bars represent the Standard Error of the Meaning. ${ }^{*} \mathrm{n}<0.05$.

\subsubsection{Elastomeric tubular grafts from fibrous scaffolds with patterned porosity from} laser phemtosecond ablation

Electrospun sheets of $10 \mathrm{~cm} \times 20 \mathrm{~cm}$ were fabricated in order to produce tubes of $10 \mathrm{~cm}$ length. By simply rolling the electrospun pPGS/PVA scaffold around various PTFE rods, followed by the curing step, tubes with various internal diameter and thickness were obtained. A SEM image of the transversal cut (Figure 4A) shows how the welding of consecutives electrospun layers occurred (connections highlighted in red dashed lines): the pPGS flowed through within the layers and was crosslinked during scaffold curing, resulting in a monolithic tubular scaffold from the electrospun scaffolds stacking. Cross-sections of tubular scaffolds of $0.73,1.35$ and $1.75 \mathrm{~mm}$ are shown on Figure 4B (i, ii and iii, respectively). Also from this technique, Y-shape tubular scaffolds, inspired on the GORE TEX® PTFE vascular grafts commercially available from Gore Medical (which are neither biodegradable, nor mimic the native ECM), was easily produced, as it can be seen on Figure 2E and on Movie S1.

The abluminal (the external side of the tubular scaffold) and the luminal (the inner side) surfaces were also analyzed through SEM (Figure 4C and D, respectively). On the abluminal side, a fibrous architecture with a preserved architecture of fibers and porosity after crosslinking was observed (Figure 4C(i)). The smooth surface of the luminal side (Figure 4E) in comparison with the surface of the abluminal side, is probably due to the contact with the PTFE surface during curing. 
A pattern of pore channels has been created by laser microablation as seen in Figure 4C ( $\mathrm{i}$ and ii). More morphological aspects of the pores are shown in Figure 4E, showing the pores are in the range of 100 microns, with diameters of $150 \mu \mathrm{m}$ for the abluminal (external) side of the tube (Figure 4(i)) and $130 \mu \mathrm{m}$ for the luminal (internal) side of the tube (Figure 4(ii)), with drop shapes (as displayed by the red dashed forms). The laser ablation process did not affect the fibrous structure or melted the polymer at the edge of the created pore (Figure 4E (iii)). More SEM images showing these and more morphological features closer can be checked at Figures S3, S4 and S5.

Therefore, the PGS/PVA tubular grafts machined by laser photoablation have two major levels of porosity: (i) the porosity from the electrospun fibers allowing the nutrients and growth factors exchange[59] and (ii) the porosity from the laser machining allowing cell migration[35,60] and, potentially, a vascular branching towards biofabricated constructs. 


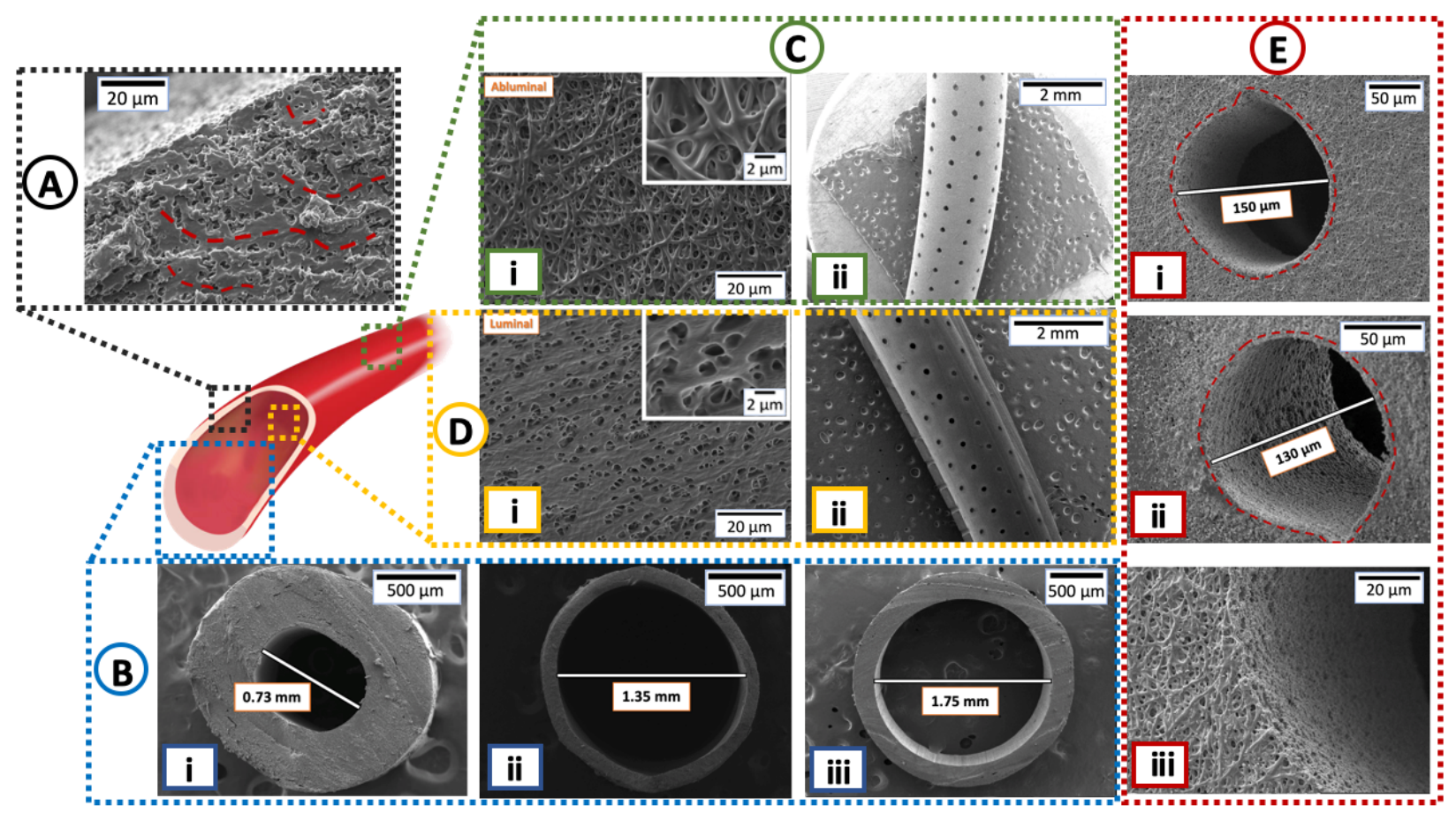

Figure 4. Morphological properties of the tubular scaffolds according to the SEM images. (A) A cross-section of a tubular scaffold, showing its inner porosity and the interlayer connection between the layers, highlighted by red dashed lines. (B) Cross-sections of tubular grafts with inner diameter of i) $0.73 \mathrm{~mm}$; ii) $1,35 \mathrm{~mm}$ and iii) $1,75 \mathrm{~mm}$ - as result from the electrospun scaffolds wrapping around TPFE mandrels - are shown. (C) The abluminal (external) surface (i), and the pores pattern resulting from the laser machining (ii). (D) The luminal (internal) surface (i) and the internal pattern of machined pores (ii). (E) The abluminal (i) and the luminal pore face (ii), respectively; (iii)The pore edge (external), evidencing the laser does not melt or fuse the fibers on their edges. 


\subsubsection{Mechanical and thermal characterizations of the vascular grafts}

Tests were performed in order to determine the mechanical properties of the PGS/PVA tubular scaffolds, to evaluate their suturability and to verify the bonding of the scaffold layers. We also characterized the effect of the laser ablation on these properties. It is worth noting that the properties discussed here were obtained from hydrated scaffolds, as they will be hydrated in the organism after implantation.

Delamination tests were first carried out with T-peel samples, simulating either the interactions inside electrospun scaffolds or the bonding between two stacked scaffolds (Figure 5A). The stacked and the directly electrospun scaffolds did not present significant differences, both resisting delamination of up to $5 \mathrm{mN} / \mathrm{mm}$, demonstrating the effectiveness of the bonding between the layers of the assembled scaffolds.

The tubular scaffolds behave as elastomeric materials (Figure 5B, Movies S1 and S2). Nonmachined and laser ablated samples, characterized by tensile tests, have presented no significant difference regarding their ultimate tensile stress at break, both with approximately $1.5 \mathrm{MPa}$ (Figure 5C). Both scaffolds were highly elastic, and could be elongated for more than $100 \%$ of their original size, though the elongation at breaking of the ablated scaffolds (140\%) increased from the non-machined scaffolds $(107 \%)$. Due to the presence of pores in the laser ablated sample the apparent Young modulus decreased from 3.11 $\pm 0.9 \mathrm{MPa}$ (non-machined) to 1.99 $\mathrm{MPa} \pm 0.2 \mathrm{MPa}$ (machined). An example of the mechanical behavior when handling is shown in Movie S3.

Finally, both non-machined and machined tubular scaffolds have shown suture retention independently of the caliber of the tube (Figure 5D). However, the suture retention for the laser 
machined scaffolds is lesser in comparison with the non-machined scaffolds $\left(3.96 \pm 0.52 \mathrm{~N} / \mathrm{mm}^{2}\right.$ and $5.85 \pm 0.46 \mathrm{~N} / \mathrm{mm}^{2}$, respectively), which was attributed to the porous structure facilitating the tearing due to force from the suture. In order to gain more insight into the viscoelastic behavior of non-machined grafts, cyclic stress-strain mechanical tests were performed on fibrous crosslinked membranes under a strain varying between 0 and $16 \%$ (Figure 5E). A strong hysteresis can be observed during the first cycle. Then, after two cycles, the stress-strain curves overlap demonstratin that no more energy is lost. This phenomenon can be quantified by the energy recovery calculated from the ratio of the area below the stress-strain curve during release over the area below the curve during stretching. An energy recovery of $10 \%$ was calculated for the first cycle whereas a recovery ranging between 42 and 52\% was calculated for the cycles 3 to 10. The low recovery of the scaffold can be explained by fiber irreversible rearrangement inducing huge energy dissipation. Then, for the third and the subsequent cycles the efficient energy recovery is due to the elastic intrinsic behavior of the crosslinked PGS and the presence of a high amount of fiber-fiber crosslinked domains.

Prior to biological assays, in order to evaluate the suitability of the vascular grafts for autoclaving, scaffolds were analyzed by thermal gravimetric analysis (TGA) (Figure 5F). The material degradation started at $200^{\circ} \mathrm{C}$, and its carbonization began at around $430^{\circ} \mathrm{C}$. As the autoclave sterilizes materials under a vapor temperature of $120^{\circ} \mathrm{C}$, the TGA analysis indicates that the scaffolds are suitable for autoclaving. Therefore, this was our sterilization method prior to the biological assays. 
A Delaminataion testing

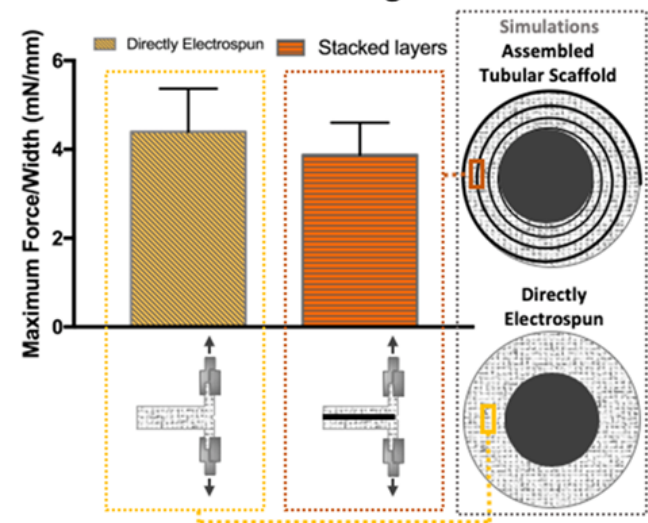

C Tensile testing

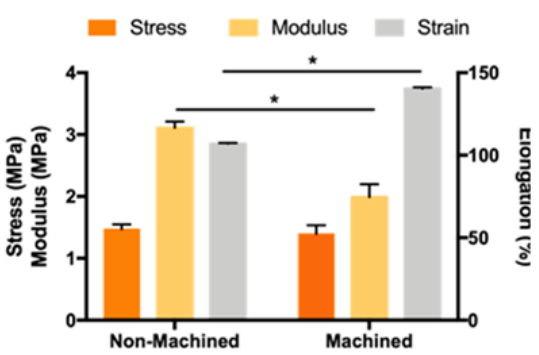

E Cyclic measurements

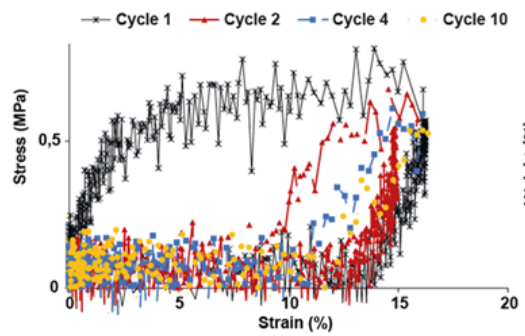

B Visual demonstration

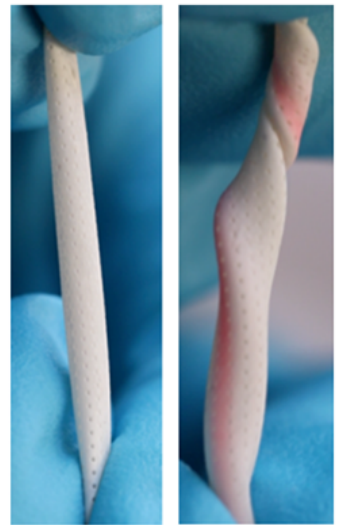

D Suture retention

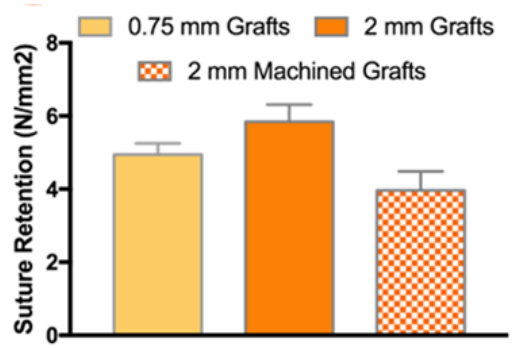

F Thermal characterisation

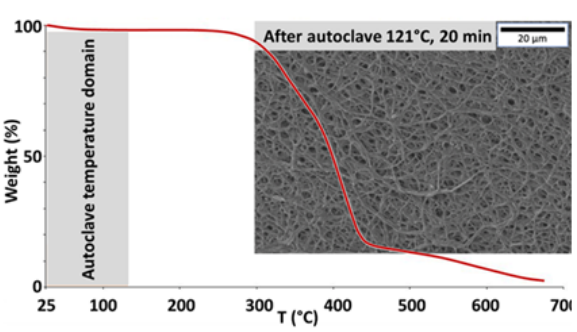

Figure 5. Thermo-mechanical properties of the elastomeric tubular scaffolds. (A) Delamination testing by uniaxial tensile assay of directly electrospun and stacked layers T-peel samples, as illustrated, simulating directly electrospun scaffolds or assembled by layers fusing, respectively. (B) Visual demonstration of the laser ablated scaffolds elasticity through gross images. The vascular graft deformation is demonstrated by a red-line (C) Ultimate tensile stress, Young's modulus and strain at break obtained from uniaxial tensile testing, of non-machined and lasermachined grafts. Error bars represent Standard Error of the Mean. *P-values $<0.05$. (D) Suture 
retention strength from uniaxial tensile testing of very small $(0.73 \mathrm{~mm})$, small $(2 \mathrm{~mm})$ and small machined PGS/PVA tubular grafts (2 mm). (E) Cyclic stress-strain curves obtained for cycles 1 , 2, 4 and 10 for a crosslinked PGS/PVA rectangular scaffold. (F) Thermogravimetric Analysis (TGA) of the suturable grafts, which demonstrates the polymer degradation (PGS/PVA) starts from $230^{\circ} \mathrm{C}$ approximately, indicating the scaffolds can be sterilized by autoclaving $\left(121^{\circ} \mathrm{C}, 20\right.$ minutes). The orange band indicates the temperature ranging of a conventional vapor autoclave. The SEM picture, obtained from an autoclaved scaffold, confirmed the scaffold structure it is not affected by autoclaving.

\subsection{Cell proliferation/cytotoxicity characterization}

For the cell proliferation/cytotoxicity characterization, results showed that endothelial cells (HUVECs) proliferated over time with both PGS/PVA scaffolds extracts and cell culture media, proving that PGS/PVA does not release harmful compounds and, therefore, has no cytotoxic effects, corroborating the analysis of Jeffries et al. with 3T3 cells [42], as seen in Figure 6. Until the day 3, the culture was stable, which was expected for both PGS/PVA extracts and control, since we started with a relatively high cell density $\left(1 \times 10^{4}\right.$ cells/well from a 96-well plate). However, at day 5 from cell seeding, the HUVEC proliferation rate was significantly higher for the PGS/PVA extracts than for the control. At day 7, once the HUVEC cells cultured with PGS/PVA extracts filled the well, the cell proliferation stabilized, probably because of the limited space of the well, while the HUVECs in non-modified media continued to proliferate and reached a similar proliferation in comparison with the PGS/PVA extracts. HUVEC cells cultured directly on PGS/PVA membranes can be seen in Figure S6. 


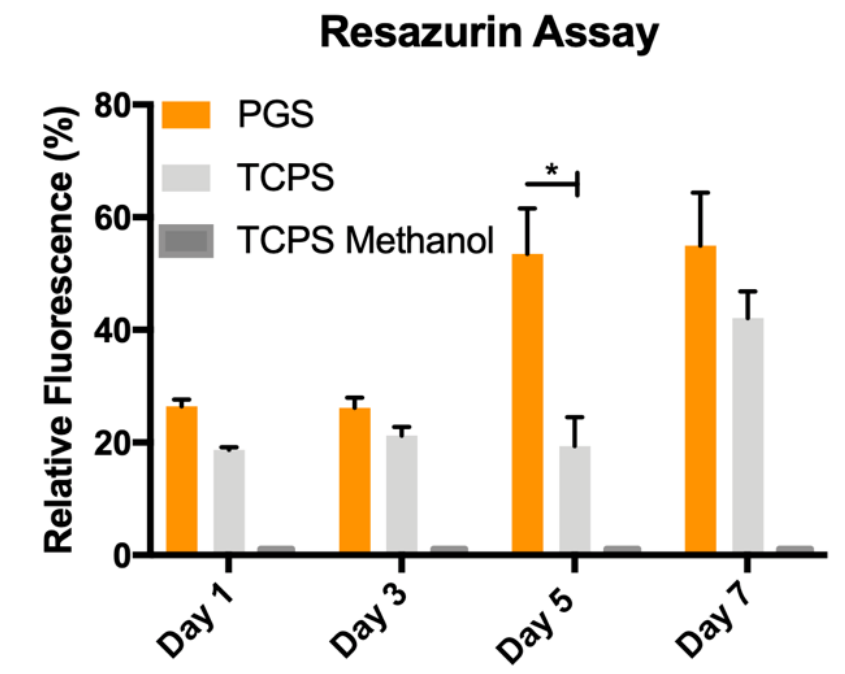

Figure 6. Resazurin cell viability assay for the HUVEC proliferation with PGS extracts. The error bars represent the Standard Error of the Meaning. ${ }^{*} \mathrm{n}<0.05$, comparing the PGS extracts with non-modified cell culture medium.

\subsection{Application of the vascular graft: an in vitro osteon-like model}

\subsubsection{Co-culture of HUVEC and MG-63 in GelMA alone: determining the expecting cell}

\section{interactions}

For co-culturing purposes, it was necessary to test if the MG-63 could be maintained in the endothelial cell media (EBM-2 + bullet kit media). MG-63 survived for, at least, four passages and proliferated at a similar rate to those cultured in DMEM media. Following, we proceeded with the MG-63/HUVEC co-culture system in the EBM-2 culture media.

HUVECs and MG-63 were firstly 3D cultured separately on scaffold-free hydrogels. After 2 days of cell culture $(48 \mathrm{~h})$, the endothelial cells formed their typical tubular structure [61] as shown in Figure 7(1A), with some of the tubes indicated by arrows, while the osteoblasts were organized in islets (Figure 7(1B)). 
However, when the HUVEC and MG-63 were co-cultured, they associated together in clusters (Figure 7(1C) interconnected by HUVEC branches, as highlighted in Figure 7(1C.1), indicated by arrows. These observations corroborate the work of Fuchs et. al. in which they describe a morphological assessment of endothelial networks formed by outgrowth endothelial cells and MG-63 [50].

\subsubsection{Osteon-like model}

A 3D osteon-like construct was prepared, composed of a vascular graft embedded in gelatin methacryloyl (GelMA) hydrogels, then seeded with MG-63 at the exterior of the vascular graft and with HUVECs at the interior of the vascular graft (Figure 1). Two kinds of osteon models were studied. The first one was built with a vascular graft without pore channels and the second was built with a laser-machined vascular graft.

For the non-machined scaffolds, due to the absence of pores, the HUVECs remained trapped inside the tubular scaffold (Figure 7(2A)), forming some tubes, indicated by an arrow in Figure 7(A.1). However, due to the high cell density (equally employed for all experiments), the cells preferably aggregated into large structures rather than capillaries [61] inside the vascular graft. At the external side of the vascular graft region, the MG-63 remained aggregated into clusters or islets (highlighted in Figure 7(2B), which is magnified in Figure 7(2B.1)), as previously observed in Figure 7(1B) for the osteoblasts seeded on GelMA without the tubular grafts. Therefore, due to the absence of machined pores, the observed structures from the HUVECs and MG-63 were similar as observed for these cell types when cultured separately.

However, when the scaffold had pores that allowed the endothelial cell to flow, these cells permeated the external surface of the hydrogel and, then, interacted with the osteoblasts at the 
external side (Figure 7(2C), magnified in Figure 7(2C.1)). We can observe how the MG-63 sprout when around the HUVECs spheroids (Figure 7(2D)). The white square, zoomed at Figure 7(D.1) shows the close cell-cell contacts, suggesting the formation of unions between the osteoblasts and HUVECs, observed by their aggregation in clusters. HUVECs can be seen as cuboid cells which organizes in clusters, and MG-63 as spindle-like cells [52,62,63] (Figure 7(2D.1)). Therefore, the laser ablated pores of the vascular graft are pivotal for the endothelial cell flow and their consecutive interaction with the cells in the biofabricated interface.
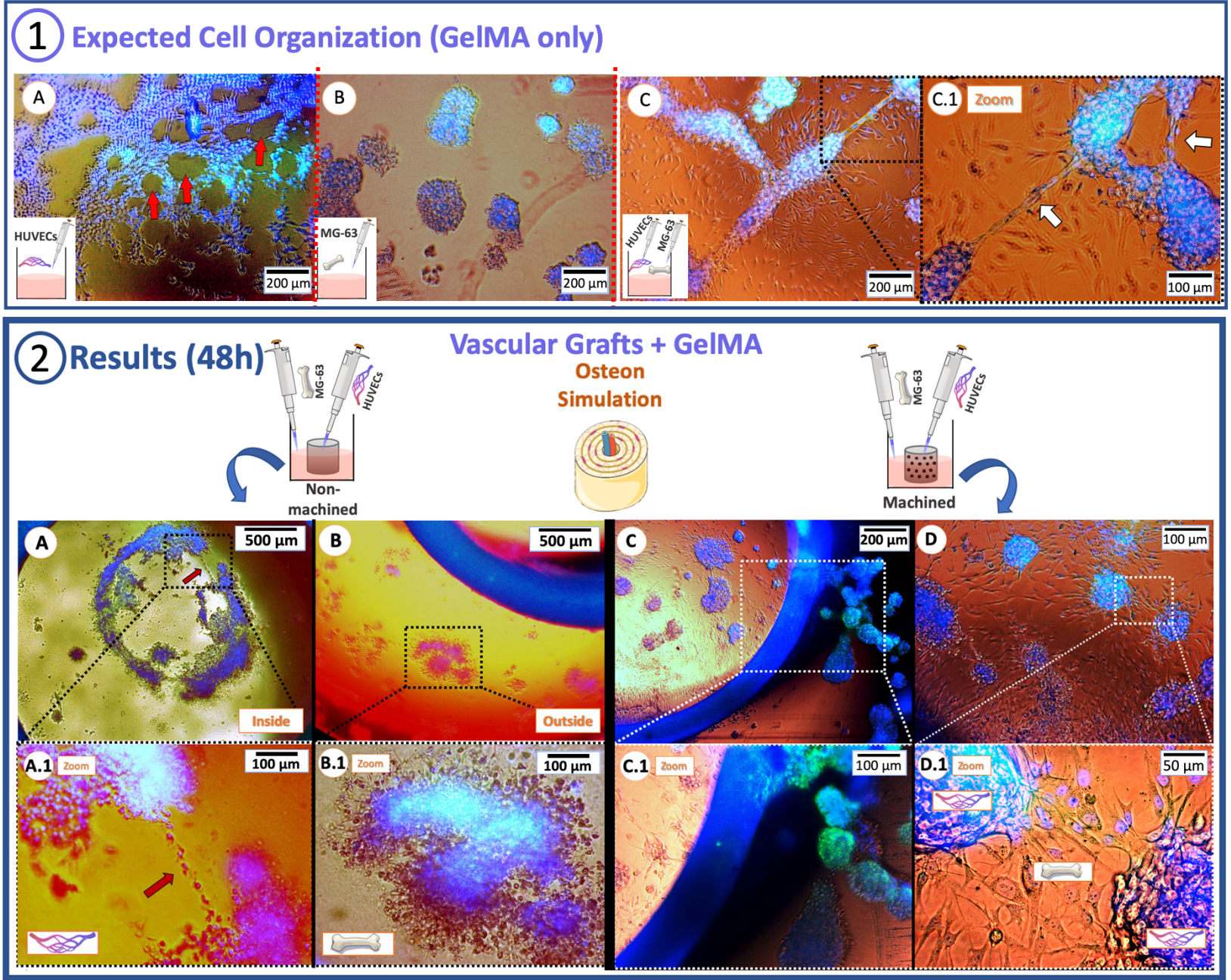

DAPI (Nuclei)

GFP (cytoskeleton) 
Figure 7. (1) 3D culture in GelMA constructs, in order to define the expected 3D structures of: (A) HUVEC cells only, with their characteristic tube formation (with some of them indicated by red arrows): (B) MG-63 osteoblasts-like only, forming circular colonies; (C) HUVEC + MG-63 co-cultures, with the association of colonies + tubular formation; (C.1) Image zoomed from the dashed area in (C), showing the structure which connects the cell colonies by white arrows. (2) After $48 \mathrm{~h}$ of cell incubation, the structures were observed in an inverted microscope. For the non-machined scaffolds, (A) at the inner side of the scaffold, seeded by endothelial cells, the dashed square is amplified in (A.1), showing the typical structure formed by the HUVECs 3D culture (pointed by red arrows); (B) At the external side of the scaffold, the expected 3D structures (islets), from osteoblasts only, are highlighted at the dashed black square, zoomed on (B.1). For the machined scaffolds, where the endothelial cells were allowed to flow towards the osteoblasts through the machined channels, exclusive structures from the interaction of endothelial cells and osteoblasts are observed in (C) and (B) and amplified in (C.1) and (D.1) respectively.

\section{DISCUSSION}

The current strategies to create vascular networks in biofabricated tissues comprises the creation of hollow channels within hydrogels populated by cells [64-66]. However, the anastomose of these channels with the host vasculature, in order to enable an instantaneous blood perfusion inside these channels, is generally not possible because of the lack of mechanical properties of hydrogels [2].

In our study, we proposed the fabrication of a small suturable vessel graft based on the elastomeric and biodegradable PGS/PVA composites, obtained by electrospinning. By 
embedding these elastomeric tubular grafts in biofabricated tissues, an anastomosis between the engineered tissue and the host vasculature could be possible.

Electrospinning enables the fabrication of tubular structures with a fibrous structure similar to the native ECM and improved mechanical strength to PGS/PVA, particularly the suture retention [42]. However, to obtain such tubular structures through electrospinning with a diameter smaller than $1 \mathrm{~mm}$ is challenging. Here, we addressed this issue by electrospinning over a non-sticky surface (parchment paper) and then rolling the obtained fibrous mats around PTFE templates. The consecutive PGS curing also bonds the successive layers of the tubular grafts.

The collection of fibers over parchment paper facilitated the detachment of all the membranes without tearing the fibers, enabling the production of tubular scaffolds (Figure 2B). Scaffolds fabricated over conductive surfaces (metal mandrels or aluminum foil, for example) cannot be detached without leaving a large amount of the product over the surface. Due to this reason, when directly electrospinning a tubular scaffold, a pre-coating step of mandrels is commonly applied [24]. Here, this step is not necessary. This strategy is indeed more efficient in terms of productivity when compared with the direct electrospinning on a small cylindrical collector and moreover it allows the precise fabrication of a tube with the desired thickness which is simply controlled by the number of employed electrospun layers. It highlights the easily customizable feature of this strategy. For example, allowing tubular scaffolds with internal diameter ranging from $0.73 \mathrm{~mm}$ (see the Movie S2) and beyond (Figure 4B) as well as diverse shapes to be obtained, as demonstrated by the fabrication of the Y-shape tube (Figure 2B and the Movie S1), and clinically relevant lengths $(10 \mathrm{~cm}$ for our prototypes, which is considered clinically relevant ( $\geq 3 \mathrm{~cm}$ )[67]). This is of crucial importance for the clinical application of these vascular grafts, either for its potential application for rapid vascularization of tissue engineered grafts, or to treat 
vascular injuries, since the scaffold caliber can be easily customized according to the vascular host site. Still, it may be possible to employ larger electrospun scaffolds to obtain longer tubes, or potentially bond various sheets to create continuous tubular scaffolds, which can be cut and employed by the surgeon according to surgery site need.

We attempted to fabricate tubular scaffolds constituted of neat PGS. However, the mass loss analysis indicated that a small amount of PVA remained even after the purification of the scaffolds in water (Figure 3E). These results corroborate the work of Jeffries et. al.[42]. who showed the difficulty in quantifying the remaining PVA employing traditional analysis such as the FT-IR spectra, as the PVA and PGS spectra are similar [42]. It is worth pointing out the remaining PVA is not harmful for cells [68-70], nor is the PGS. PVA is non-toxic, biodegradable, and does not degrade in any harm compounds to the cells [71-74]. These are essential features, as the scaffolds are intended to be applied as bioabsorbable vascular grafts.

To promote a vascular branching from the vascular graft towards the interior of the biofabricated tissue, we created a pattern of pore channels across the wall of the tubular grafts through laser femtosecond ablation, or laser machining (Figure 4C, D and E; and Movie S3). Since endothelial cells have $13.2 \pm 4.1 \mu \mathrm{m}$ width and $25.8 \pm 8.5 \mu \mathrm{m}$ length [75], these pores dimensions $(\cong 150 \mu \mathrm{m})$ can, therefore, support endothelial cell migration and potentially allow blood flow and thus create a vascular micro-networking from the vascular graft to the biofabricated implant. However, it is worth questioning how the vascular grafts with the patterned pores will behave once it is connected to the host vasculature and whether it will allow angiogenesis to occur inside the fabricated tissue engineering construct. Future experiments in vivo could investigate how the pores size and the graft wall thickness affect the vascular branching. However, is worth considering that these variables could adversely affect the 
mechanical properties of the vascular grafts. We hypothesized that, as the blood flows outside and goes in contact with the external tissue, it will coagulate the pores, as the coagulum formation is part of the dynamics of angiogenesis process [76]. Though the coagulation inside the machined pores can be beneficial concerning the dynamic of angiogenesis and vascular branching, however, for in vivo studies, we suggest to previously soak these tubular scaffolds in heparin, an anticoagulant that can prevent blood clot formation inside the lumen of the vascular grafts as natural response from the organism at the implant site and that can also enhance endothelial cell recruitment [77]. The smooth luminal surface in the interior of the tubular scaffolds can be an interesting feature (Figure 4D), potentially helping to prevent turbulent blood flow, if the scaffolds are intended to be employed as vascular grafts or artificial arteries. Moreover, because there is a crescent clinical need of small diameter vascular grafts $(\mathrm{D}<6 \mathrm{~mm})$ to treat vascular diseases, as for coronary artery bypass grafting and some peripheral vascular diseases $[78,24,79]$, the scaffolds without the ablated pores can potentially be applied as smalldiameter vascular grafts, for some vascular treatments. Through quasi-static and cyclic mechanical analysis, we demonstrated the scaffolds have an intrinsic elastic behavior, thanks to the PGS and fibrous architecture of the scaffolds, being potentially suitable for vascular tissue engineering. However, for this specific application, more mechanical testing must be carried in order to evaluate the compliance of these scaffolds, comparing the described grafts with natural arteries, as well with previously described artificial arteries. The causes of the increase in cell proliferation for HUVEC cells treated with PGS extracts for 5 days (Figure 6) remains unclear. For future works, we suggest deeper investigations at molecular level (e.g. qPCR) in order to stablish a hypothesis for this observation. 
To demonstrate the potential of the laser machined pores on vascular grafts for the task of rapid vascularization of biofabricated constructs, we created an osteon-like in vitro model that simulates the rapid endothelial cell perfusion from the scaffolds towards a 3D bone-like biofabricated construct (Figure 1), through the pores. From the observations on MG-63 and HUVECs co-cultured on GelMA hydrogels without the vascular graft (Figure 7(1C and D)), compared with the two cell types cultured separately on GelMA (Figure 7A and B), we hypothesized that both cell types would interact and form exclusive aggregations (connected clusters) that would allow the endothelial cells, which were seeded at inside of the vascular graft, to flow towards the osteoblasts seeded at the exterior of the vascular graft. Confirming our assumptions, the endothelial cells permeated the external surface of the hydrogel, thanks to the laser-machined pores and, then, interacted with the osteoblasts at the external side, forming connected clusters (Figure 7(2C and 2C.1)), with sprout MG-63 around the HUVEC clusters (Figure 7(2D.1)). These interactions are pivotal for the proliferation and survival of both cell types [2,6]: according to Shi et. al. [52], the MG-63 play a positive role in HUVEC cells proliferation, while endothelial cells are known to secret osteogenic growth factors that enhance the survival and the proliferation of osteoblasts [80]. On the other hand, osteoblasts secrets VEGF in enough quantities to increase the cell proliferation and survival of endothelial cells [81]. We suggest investigating this interaction at the molecular level (i.e. Polymerase Chain Reverse Transcription, or PCR-rt) to better understand how this crosstalk works and, therefore, to better predict this behavior once the constructs are sutured into the host. Complex crosstalks occur in a complex way in the organism, with hundreds of cell types regulating each other in harmony [43]. The importance to reproduce these crosstalks on in vitro models leads to an increasing in the employment of co-culture systems [82]. 
Based on that, it may be likely probable the permeability of the vascular grafts allows the crosstalk of cell-secreted growth factors from MG-63 and HUVECs which stimulates the cell migrations, while the laser machined pores allow the cell flows/migrations. Still, more investigations at the molecular level have to be made to gain more insight such interaction. Therefore, regarding potential applications in bone tissue engineering, when inserting the elastomeric tubular grafts with laser machined pores in biofabricated bone, the presence of a vascular networking may increase the bone formation, while the bone cells may contribute to improve the construct vasculature in a dynamic effect $[83,84]$. Moreover, it has been reported that not only growth factors, but also a direct contact with endothelial cells, has a positive effect on the alkaline phosphatase activity of osteoblasts [85]. Besides, this vascular network can later serve as template for ossification, which happens thanks to the synergistic interactions between osteoblasts and endothelial cells [86].

It is also worthy to point out that, in the lumen of the scaffolds, we can find some clusters associations of HUVECs/MG-63 (Figure 7(2C)), though less developed than at the external side. Inevitably, during the MG-63 seeding, some cells can also go into the lumen through the laser machined pores. In order to avoid this association, for further works, we suggest to bioprint the bone construct with a bioink from the association of GelMA and osteoblasts (or another bioink of interest), embedding the tubular scaffold inside the structure and to perfuse the endothelial cells by through a bioreactor, controlling the spatial distribution of both cell lines. For further studies, we also suggest localizing the two cell-types by immunofluorescence with specific cell markers for each cell type. Moreover, to observe filopodia and lamellipodia, structures present in migrating cells [87], scanning electron microscopy can be employed in future works to 
investigate the cell migration in a more refined level. Future in vivo essays implanting functional pre-vascularized constructs will be essential to understand their function in vivo.

This work gives an example of application through the creation of an osteon-like construct as model of rapid in vitro vascularization/cell migration. Furthermore, combining our machined vascular grafts with other biofabrication and/or bioprinting techniques such as Freeform Reversible Embedding of Suspended Hydrogels (FRESH)[88] or integrated tissue-organ printer (ITOP), more complexed structures could even be explored. Moreover, although PGS is known as a fast degrading polymer, its use for long term applications such as cell-free arterial grafts has been recently demonstrated. As an example, Allen et al.[89] embedded a PGS graft obtained from salt leaching technique inside a thin envelop of electrospun PCL membrane in order to insure the mechanical integrity of the composite graft along one year of implantation. Using exactly the same strategy, our PGS grafts could also be embedded in a protective electrospun shell but with the advantage of the presence of the machined pores that may facilitate the vascularization. In addition, modified PGS could be synthesized and further processed by electrospinning allowing thus the adjustment of the properties of the construct along its degradation. For example, Wang et al. studied the effects of grafting polyethylene glycol on PGS on the mechanical and biological properties.[90] More recently, palmitic acid modified PGS was proposed by Fu et al. for the fabrication of artery grafts by the salt leaching technique.[91] The grafting of carboxylic acid on the free hydroxyl groups of PGS slowed down the overall degradation of the modified PGS graft while insuring limited inflammatory responses as well as good mechanical properties along the degradation process. Similarly, electrospinning of palmitic acid modified PGS could be envisaged in order to fabricate electrospun membranes which can be further processed and laser-machined to obtain vascular grafts with patterned porosity. 


\section{CONCLUSION}

We developed a small, suturable, biodegradable and biomimetic vascular tubular scaffold to be integrated in 3D biofabricated tissue engineered grafts to potentially provide an anchor site to the biofabricated graft and an immediate blood perfusion. We described a simple and fast method to produce elastomeric and biodegradable PGS/PVA vascular grafts from electrospinning that can be customized regarding their inner diameter (being as small as $0.73 \mathrm{~mm}$ ), wall thickness, length, and even their shape (straight tube and Y-shape). Pore channels in the order of 100 microns were machined by laser femtosecond photoablation across the wall of the tubular scaffold. These pore channels were opened in order to provide an immediate blood perfusion and also rapid vascularization. The tubular scaffolds have a biomimetic architecture that resembles the native extracellular matrix. Preliminary mechanical characterization have shown that they stand the mechanical requirements for suturability and elasticity for potential application as vascular grafts, being suitable to be incorporated into tissue engineered grafts and to be directly connected within the host blood stream. Moreover, they may also be applied as bypass conduit to treat vascular diseases, as there is a crescent clinical need of small diameter vascular grafts. Nevertheless, supplementary mechanical characterizations need to be carried out in order to evaluate the effect of in vivo degradability on their strength and conclude on long term applications. To demonstrate the potential of application, an osteon-like model for rapid endothelialization was assembled from the integration of the vascular grafts inside 3D GelMA hydrogels which was dynamically seeded with endothelial cells inside the graft and osteoblasts outside. Thanks to the laser machined pores, the endothelial cells can permeate to the external side of the vascular grafts and interact with the 3D culture of osteoblasts, generating new 3D 
structures. Therefore, the customizable, bioabsorbable and biomimetic suturable vascular grafts developed in this work, with an engineered pattern of laser micro-ablated pores, can be embedded into 3D tissue engineered constructs, in order to potentially promote a vascular branching inside the constructs and serving as anchor site, improving the integration of these constructs with the host. This approach offers new prospects to tissue engineers to improve the survival and to advance the clinical translation of biofabricated tissues.

\section{ASSOCIATED CONTENT}

\section{Supporting Information}

The Supporting Information is available free of charge on the IOPscience website at DOI: [[[To be defined]]]

Schematic of fluorescent images assembly, NMR+ analysis of the pPGS (1:1 molar rate) employed, SEM images of the tubular scaffold processed by laser microablation, SEM images of details of the laser machined pores created, SEM pictures from the details of the laser machined tubular scaffolds, optical microscopy images of PGS membranes cultured with HUVEC cells $(\mathrm{PDF})$

Movie S1, Bioresorbable Bifurcated Vascular Grafts obtained from Electrospinning (MPG).

Movie S2, Super Small PGS Vessel Graft (MPG).

Movie S3, Laser Machined Vascular Grafts (MPG). 


\section{Corresponding Author}

*E-mail: guy.schlatter@unistra.fr (G.S.)

\section{Notes}

The authors declare no competing financial interest.

\section{Funding Sources}

This work has been financed by the Fundação de Amparo à Pesquisa do Estado de São Paulo (FAPESP, process n 2014/17939-0 and process nº 2016/04418-8), by the Coordenação de Aperfeiçoamento de Pessoal de Nível Superior - Brasil (CAPES) - Finance Code 001, by funds from the Agence Nationale de la Recherche (MimHeart project ANR-15-CE08-0010-02) and from Institut Carnot MICA (project ElectrATPulp).

\section{ACKNOWLEDGMENT}

We would like to thank Frédéric Mermet from IREPA LASER (Strasbourg, France) for the laser micromachining of the tubular constructs.

\section{REFERENCES}


[1] Novosel E C, Kleinhans C and Kluger P J 2011 Vascularization is the key challenge in tissue engineering Advanced drug delivery reviews 63 300-11

[2] Rouwkema J and Khademhosseini A 2016 Vascularization and angiogenesis in tissue engineering: beyond creating static networks Trends in biotechnology 34 733-45

[3] Carmeliet P 2000 Mechanisms of angiogenesis and arteriogenesis. Nature medicine $6389-$ 95

[4] Jain R K, Au P, Tam J, Duda D G and Fukumura D 2005 Engineering vascularized tissue Nat Biotech 23 821-3

[5] Kannan R Y, Salacinski H J, Sales K, Butler P and Seifalian A M 2005 The roles of tissue engineering and vascularisation in the development of micro-vascular networks: a review Biomaterials 26 1857-75

[6] Rouwkema J, Rivron N C and van Blitterswijk C A 2008 Vascularization in tissue engineering. Trends in biotechnology 26 434-41

[7] Clark E R and Clark E L 1939 Microscopic observations on the growth of blood capillaries in the living mammal American Journal of Anatomy 64 251-301

[8] Jafarian M, Eslaminejad M B, Khojasteh A, Mashhadi Abbas F, Dehghan M M, Hassanizadeh R and Houshmand B 2008 Marrow-derived mesenchymal stem cells-directed bone regeneration in the dog mandible: a comparison between biphasic calcium phosphate and natural bone mineral. Oral surgery, oral medicine, oral pathology, oral radiology, and endodontics 105 e14-24

[9] Barnes C P, Sell S A, Boland E D, Simpson D G and Bowlin G L 2007 Nanofiber technology: designing the next generation of tissue engineering scaffolds. Advanced drug delivery reviews $\mathbf{5 9} 1413-33$

[10] Langer R and Vacanti J P 1993 Tissue engineering Science $260920-6$

[11] Cleary M A, Geiger E, Grady C, Best C, Naito Y and Breuer C 2012 Vascular tissue engineering: the next generation Trends in molecular medicine 18 394-404

[12] Seifu D G, Purnama A, Mequanint K and Mantovani D 2013 Small-diameter vascular tissue engineering Nature Reviews Cardiology 10410

[13] Crapo P M, Gilbert T W and Badylak S F 2011 An overview of tissue and whole organ decellularization processes Biomaterials 32 3233-43

[14] Shirakigawa N and Ijima H 2017 Decellularized tissue engineering Advances in Biomaterials for Biomedical Applications (Springer) pp 185-226

[15] Wang Z, Liu L, Mithieux S M and Weiss A S 2020 Fabricating organized elastin in vascular grafts Trends in Biotechnology 
[16] Leyh R G, Wilhelmi M, Walles T, Kallenbach K, Rebe P, Oberbeck A, Herden T, Haverich A and Mertsching H 2003 Acellularized porcine heart valve scaffolds for heart valve tissue engineering and the risk of cross-species transmission of porcine endogenous retrovirus The Journal of thoracic and cardiovascular surgery 126 1000-4

[17] Hasan A, Memic A, Annabi N, Hossain M, Paul A, Dokmeci M R, Dehghani F and Khademhosseini A 2014 Electrospun scaffolds for tissue engineering of vascular grafts. Acta biomaterialia 10 11-25

[18] Shin N G R and C S S and H 2013 Current approaches to electrospun nanofibers for tissue engineering Biomedical Materials 814102

[19] Jia L, Prabhakaran M P, Qin X and Ramakrishna S 2013 Stem cell differentiation on electrospun nanofibrous substrates for vascular tissue engineering. Materials science \& engineering. C, Materials for biological applications 33 4640-50

[20] Abdal-hay A, Bartnikowski M, Hamlet S and Ivanovski S 2018 Electrospun biphasic tubular scaffold with enhanced mechanical properties for vascular tissue engineering Materials Science and Engineering: $C 82$ 10-8

[21] Wu H, Fan J, Chu C-C and Wu J 2010 Electrospinning of small diameter 3-D nanofibrous tubular scaffolds with controllable nanofiber orientations for vascular grafts Journal of Materials Science: Materials in Medicine 21 3207-15

[22] Ferrari P F, Aliakbarian B, Lagazzo A, Tamayol A, Palombo D and Perego P 2017 Tailored electrospun small-diameter graft for vascular prosthesis International Journal of Polymeric Materials and Polymeric Biomaterials 66 635-43

[23] Marcolin C, Draghi L, Tanzi M and Faré S 2017 Electrospun silk fibroin-gelatin composite tubular matrices as scaffolds for small diameter blood vessel regeneration Journal of Materials Science: Materials in Medicine 2880

[24] Rocco K A, Maxfield M W, Best C A, Dean E W and Breuer C K 2014 In Vivo Applications of Electrospun Tissue-Engineered Vascular Grafts: A Review Tissue Engineering Part B: Reviews 20 628-40

[25] Kishan A P and Cosgriff-Hernandez E M 2017 Recent advancements in electrospinning design for tissue engineering applications: a review Journal of Biomedical Materials Research Part A

[26] Zhang D and Chang J 2008 Electrospinning of Three-Dimensional Nanofibrous Tubes with Controllable Architectures Nano Lett. 8 3283-7

[27] Dinis T M, Elia R, Vidal G, Dermigny Q, Denoeud C, Kaplan D L, Egles C and Marin F 2015 3D multi-channel bi-functionalized silk electrospun conduits for peripheral nerve regeneration Journal of the Mechanical Behavior of Biomedical Materials 41 43-55 
[28] Belanger K, Schlatter G, Hébraud A, Marin F, Testelin S, Dakpé S, Devauchelle B and Egles C 2018 A multi-layered nerve guidance conduit design adapted to facilitate surgical implantation Health Science Reports 1 e86

[29] Nam J, Huang Y, Agarwal S and Lannutti J 2007 Improved cellular infiltration in electrospun fiber via engineered porosity Tissue engineering $132249-57$

[30] Wittmer C R, Hébraud A, Nedjari S and Schlatter G 2014 Well-organized 3D nanofibrous composite constructs using cooperative effects between electrospinning and electrospraying Polymer 55 5781-7

[31] Garcia Garcia A, Hébraud A, Duval J-L, Wittmer C R, Gaut L, Duprez D, Egles C, Bedoui F, Schlatter G and Legallais C 2018 Poly( $\varepsilon$-caprolactone)/Hydroxyapatite 3D Honeycomb Scaffolds for a Cellular Microenvironment Adapted to Maxillofacial Bone Reconstruction ACS Biomater. Sci. Eng. 4 3317-26

[32] Soliman S, Sant S, Nichol J W, Khabiry M, Traversa E and Khademhosseini A 2011 Controlling the porosity of fibrous scaffolds by modulating the fiber diameter and packing density Journal of Biomedical Materials Research Part A 96 566-74

[33] Yixiang D, Yong T, Liao S, Chan C K and Ramakrishna S 2008 Degradation of electrospun nanofiber scaffold by short wave length ultraviolet radiation treatment and its potential applications in tissue engineering Tissue Engineering Part A 14 1321-9

[34] Baker B M, Gee A O, Metter R B, Nathan A S, Marklein R A, Burdick J A and Mauck R L 2008 The potential to improve cell infiltration in composite fiber-aligned electrospun scaffolds by the selective removal of sacrificial fibers Biomaterials 29 2348-58

[35] Lee B L-P, Jeon H, Wang A, Yan Z, Yu J, Grigoropoulos C and Li S 2012 Femtosecond laser ablation enhances cell infiltration into three-dimensional electrospun scaffolds Acta Biomaterialia 8 2648-58

[36] Lim Y C, Johnson J, Fei Z, Wu Y, Farson D F, Lannutti J J, Choi H W and Lee L J 2011 Micropatterning and characterization of electrospun poly ( $\varepsilon$-caprolactone)/gelatin nanofiber tissue scaffolds by femtosecond laser ablation for tissue engineering applications Biotechnology and bioengineering 108 116-26

[37] McCullen S D, Gittard S D, Miller P R, Pourdeyhimi B, Narayan R J and Loboa E G 2011 Laser Ablation Imparts Controlled Micro-Scale Pores in Electrospun Scaffolds for Tissue Engineering Applications Annals of Biomedical Engineering 393021

[38] Srinivasan R 1986 Ablation of polymers and biological tissue by ultraviolet lasers Science $234559-65$

[39] Rai R, Tallawi M, Grigore A and Boccaccini A R 2012 Synthesis, properties and biomedical applications of poly(glycerol sebacate) (PGS): A review Progress in Polymer Science 37 1051-78 
[40] Wang Y, Ameer G A, Sheppard B J and Langer R 2002 A tough biodegradable elastomer Nat Biotech 20 602-6

[41] Shenoy S L, Bates W D, Frisch H L and Wnek G E 2005 Role of chain entanglements on fiber formation during electrospinning of polymer solutions: good solvent, non-specific polymer-polymer interaction limit Polymer 46 3372-84

[42] Jeffries E M, Allen R A, Gao J, Pesce M and Wang Y 2015 Highly elastic and suturable electrospun poly(glycerol sebacate) fibrous scaffolds Acta Biomaterialia 18 30-9

[43] Alberts B, Bray D, Hopkin K, Johnson A, Lewis J, Raff M, Roberts K and Walter P 2013 Essential cell biology (Garland Science)

[44] Weiner S and Wagner H D 1998 The material bone: structure-mechanical function relations Annual review of materials science 28 271-98

[45] Yue K, Trujillo-de Santiago G, Alvarez M M, Tamayol A, Annabi N and Khademhosseini A 2015 Synthesis, properties, and biomedical applications of gelatin methacryloyl (GelMA) hydrogels Biomaterials 73 254-71

[46] McKee M G, Wilkes G L, Colby R H and Long T E 2004 Correlations of solution rheology with electrospun fiber formation of linear and branched polyesters Macromolecules $\mathbf{3 7}$ $1760-7$

[47] Chaouat M, Le Visage C, Baille W E, Escoubet B, Chaubet F, Mateescu M A and Letourneur D 2008 A Novel Cross-linked Poly(vinyl alcohol) (PVA) for Vascular Grafts Advanced Functional Materials 18 2855-61

[48] Li X, Hong A T-L, Naskar N and Chung H-J 2015 Criteria for Quick and Consistent Synthesis of Poly(glycerol sebacate) for Tailored Mechanical Properties Biomacromolecules 16 1525-33

[49] Czekanska E M 2011 Assessment of cell proliferation with resazurin-based fluorescent dye Mammalian Cell Viability (Springer) pp 27-32

[50] Fuchs S, Hofmann A and Kirkpatrick C J 2007 Microvessel-like structures from outgrowth endothelial cells from human peripheral blood in 2-dimensional and 3-dimensional cocultures with osteoblastic lineage cells Tissue engineering 13 2577-88

[51] Kyriakidou K, Lucarini G, Zizzi A, Salvolini E, Mattioli Belmonte M, Mollica F, Gloria A and Ambrosio L 2008 Dynamic co-seeding of osteoblast and endothelial cells on 3D polycaprolactone scaffolds for enhanced bone tissue engineering Journal of bioactive and compatible polymers $23227-43$

[52] Shi B, Andrukhov O, Berner S, Schedle A and Rausch-Fan X 2014 The angiogenic behaviors of human umbilical vein endothelial cells (HUVEC) in co-culture with osteoblast-like cells (MG-63) on different titanium surfaces Dental Materials 30 839-47 
[53] Unger R E, Sartoris A, Peters K, Motta A, Migliaresi C, Kunkel M, Bulnheim U, Rychly J and Kirkpatrick C J 2007 Tissue-like self-assembly in cocultures of endothelial cells and osteoblasts and the formation of microcapillary-like structures on three-dimensional porous biomaterials. Biomaterials 28 3965-76

[54] Zhang Y, Schedle A, Matejka M, Rausch-Fan X and Andrukhov O 2010 The proliferation and differentiation of osteoblasts in co-culture with human umbilical vein endothelial cells: an improved analysis using fluorescence-activated cell sorting Cellular \& molecular biology letters 15517

[55] Clover J and Gowen M 1994 Are MG-63 and HOS TE85 human osteosarcoma cell lines representative models of the osteoblastic phenotype? Bone 15 585-91

[56] Masters J R 2000 Human cancer cell lines: fact and fantasy Nature reviews Molecular cell biology 1233

[57] Goodwin A M 2007 In vitro assays of angiogenesis for assessment of angiogenic and antiangiogenic agents Microvascular research 74 172-83

[58] Hassan C and Peppas N 2000 Structure and applications of poly (vinyl alcohol) hydrogels produced by conventional crosslinking or by freezing/thawing methods Biopolymers. PVA Hydrogels, Anionic Polymerisation Nanocomposites 37-65

[59] Ngadiman N H A, Noordin M Y, Idris A and Kurniawan D 2017 A review of evolution of electrospun tissue engineering scaffold: From two dimensions to three dimensions Proceedings of the Institution of Mechanical Engineers, Part H: Journal of Engineering in Medicine 231 597-616

[60] Hollister S J 2005 Porous scaffold design for tissue engineering Nature materials 4518

[61] Arnaoutova I, George J, Kleinman H K and Benton G 2009 The endothelial cell tube formation assay on basement membrane turns 20: state of the science and the art Angiogenesis 12 267-74

[62] Hofmann A, Ritz U, Verrier S, Eglin D, Alini M, Fuchs S, Kirkpatrick C J and Rommens P M 2008 The effect of human osteoblasts on proliferation and neo-vessel formation of human umbilical vein endothelial cells in a long-term 3D co-culture on polyurethane scaffolds Biomaterials 29 4217-26

[63] PAUTKE C, SCHIEKER M, TISCHER T, KOLK A, NETH P, MUTSCHLER W and MILZ S 2004 Characterization of osteosarcoma cell lines MG-63, Saos-2 and U-2 OS in comparison to human osteoblasts Anticancer research 24 3743-8

[64] Moroni L, Burdick J A, Highley C, Lee S J, Morimoto Y, Takeuchi S and Yoo J J 2018 Biofabrication strategies for 3D in vitro models and regenerative medicine Nature Reviews Materials 3 
[65] Clyne A M, Swaminathan S and Lantada A D 2019 Biofabrication strategies for creating microvascular complexity Biofabrication 11032001

[66] Gao G, Kim B S, Jang J and Cho D-W 2019 Recent Strategies in Extrusion-Based ThreeDimensional Cell Printing toward Organ Biofabrication ACS Biomaterials Science \& Engineering 5 1150-69

[67] L'Heureux N, Dusserre N, Konig G, Victor B, Keire P, Wight T N, Chronos N A F, Kyles A E, Gregory C R, Hoyt G, Robbins R C and McAllister T N 2006 Human tissueengineered blood vessels for adult arterial revascularization Nat Med 12 361-5

[68] Mathews D T, Birney Y A, Cahill P A and McGuinness G B 2008 Vascular cell viability on polyvinyl alcohol hydrogels modified with water-soluble and -insoluble chitosan Journal of Biomedical Materials Research Part B: Applied Biomaterials 84B 531-40

[69] Fatih Canbolat M, Tang C, Bernacki S H, Pourdeyhimi B and Khan S 2011 Mammalian Cell Viability in Electrospun Composite Nanofiber Structures Macromolecular Bioscience 11 1346-56

[70] Mahmoud K A, Mena J A, Male K B, Hrapovic S, Kamen A and Luong J H T 2010 Effect of Surface Charge on the Cellular Uptake and Cytotoxicity of Fluorescent Labeled Cellulose Nanocrystals ACS Applied Materials \& Interfaces 2 2924-32

[71] Baker M I, Walsh S P, Schwartz Z and Boyan B D 2012 A review of polyvinyl alcohol and its uses in cartilage and orthopedic applications Journal of Biomedical Materials Research Part B: Applied Biomaterials 100 1451-7

[72] Burstein N L 1980 Corneal cytotoxicity of topically applied drugs, vehicles and preservatives Survey of ophthalmology 25 15-30

[73] DeMerlis C C and Schoneker D R 2003 Review of the oral toxicity of polyvinyl alcohol (PVA) Food and Chemical Toxicology 41 319-26

[74] Wang M, Li Y, Wu J, Xu F, Zuo Y and Jansen J A 2008 In vitro and in vivo study to the biocompatibility and biodegradation of hydroxyapatite/poly (vinyl alcohol)/gelatin composite Journal of Biomedical Materials Research Part A 85 418-26

[75] Garipcan B, Maenz S, Pham T, Settmacher U, Jandt K D, Zanow J and Bossert J 2011 Image analysis of endothelial microstructure and endothelial cell dimensions of human arteries-a preliminary study Advanced Engineering Materials $\mathbf{1 3}$

[76] Browder T, Folkman J and Pirie-Shepherd S 2000 The hemostatic system as a regulator of angiogenesis Journal of Biological Chemistry 275 1521-4

[77] Sarkar S, Sales K M, Hamilton G and Seifalian A M 2007 Addressing thrombogenicity in vascular graft construction Journal of Biomedical Materials Research Part B: Applied Biomaterials 82 100-8 
[78] Seifu D G, Purnama A, Mequanint K and Mantovani D 2013 Small-diameter vascular tissue engineering Nature Reviews Cardiology 10410

[79] Bouchet M, Gauthier M, Maire M, Ajji A and Lerouge S 2019 Towards compliant smalldiameter vascular grafts: Predictive analytical model and experiments Materials Science and Engineering: $C$ 100 715-23

[80] Villars F, Bordenave L, Bareille R and Amedee J 2000 Effect of human endothelial cells on human bone marrow stromal cell phenotype: role of VEGF? Journal of cellular biochemistry 79 672-85

[81] Furumatsu T, Shen Z N, Kawai A, Nishida K, Manabe H, Oohashi T, Inoue H and Ninomiya Y 2003 Vascular endothelial growth factor principally acts as the main angiogenic factor in the early stage of human osteoblastogenesis Journal of biochemistry 133 633-9

[82] Kirkpatrick C J, Wagner M, Hermanns I, Klein C L, Köhler H, Otto M, Van Kooten T G and Bittinger F 1997 Physiology and cell biology of the endothelium: a dynamic interface for cell communication International Journal of Microcirculation 17 231-40

[83] Kang Y, Kim S, Fahrenholtz M, Khademhosseini A and Yang Y 2013 Osteogenic and angiogenic potentials of monocultured and co-cultured human-bone-marrow-derived mesenchymal stem cells and human-umbilical-vein endothelial cells on three-dimensional porous beta-tricalcium phosphate scaffold. Acta biomaterialia 9 4906-15

[84] Nguyen L H, Annabi N, Nikkhah M, Bae H, Binan L, Park S, Kang Y, Yang Y and Khademhosseini A 2012 Vascularized Bone Tissue Engineering: Approaches for Potential Improvement Tissue Engineering Part B: Reviews 18 363-82

[85] Stahl A, Wenger A, Weber H, Stark G B, Augustin H G and Finkenzeller G 2004 Bidirectional cell contact-dependent regulation of gene expression between endothelial cells and osteoblasts in a three-dimensional spheroidal coculture model Biochemical and biophysical research communications 322 684-92

[86] Vattikuti R and Towler D A 2004 Osteogenic regulation of vascular calcification: an early perspective American Journal of Physiology-Endocrinology And Metabolism 286 E686-96

[87] Mejillano M R, Kojima S, Applewhite D A, Gertler F B, Svitkina T M and Borisy G G 2004 Lamellipodial versus filopodial mode of the actin nanomachinery: pivotal role of the filament barbed end Cell 118 363-73

[88] Hinton T J, Jallerat Q, Palchesko R N, Park J H, Grodzicki M S, Shue H-J, Ramadan M H, Hudson A R and Feinberg A W 2015 Three-dimensional printing of complex biological structures by freeform reversible embedding of suspended hydrogels Science advances 1 e1500758

[89] Allen R A, Wu W, Yao M, Dutta D, Duan X, Bachman T N, Champion H C, Stolz D B, Robertson A M, Kim K, Isenberg J S and Wang Y 2014 Nerve regeneration and elastin 
formation within poly(glycerol sebacate)-based synthetic arterial grafts one-year postimplantation in a rat model Biomaterials 35 165-73

[90] Wang Y, Wu H, Wang Z, Zhang J, Zhu J, Ma Y, Yang Z and Yuan Y 2019 Optimized Synthesis of Biodegradable Elastomer PEGylated Poly(glycerol sebacate) and Their Biomedical Application Polymers 11

[91] Fu J, Ding X, Stowell C E T, Wu Y-L and Wang Y 2020 Slow degrading poly(glycerol sebacate) derivatives improve vascular graft remodeling in a rat carotid artery interposition model Biomaterials 257120251

[92] Ma H, Burger C, Hsiao B S and Chu B 2011 Ultra-fine cellulose nanofibers: new nanoscale materials for water purification J. Mater. Chem. 21 7507-10 